\title{
Meroindenon and Merochlorins E and F, Antibacterial Meroterpenoids from a Marine-Derived Sediment Bacterium of the Genus Streptomyces
}

Min-Ji Ryu, ${ }^{\dagger}$ Sunghoon Hwang, $₫$ Sojeong Kim, $₫$ Inho Yang, " Dong-Chan Oh, $₫$ Sang-Jip Nam,,${ }^{*} \dagger$ and William Fenical ${ }^{*}, \nabla$ 'Department of Chemistry and Nanoscience, Ewha Womans University, Seoul 03760, Republic of Korea

"Natural Products Research Institute, College of Pharmacy, Seoul National University, Seoul 08826, Republic of Korea

$\S_{\text {}}$ Graduate School of Industrial Pharmaceutical Sciences, Ewha Womans University, Seoul 03760, Republic of Korea

" Department of Convergence Study on the Ocean Science and Technology, Korea Maritime and Ocean University, Busan 49112, Republic of Korea

${ }^{\nabla}$ Center for Marine Biotechnology and Biomedicine, Scripps Institution of Oceanography, University of California San Diego, La Jolla, California 92093-0204, United States 


\section{Table of Contents}

General experimental procedures

Collection and phylogenetic analysis of strain $\mathrm{CNH}-189$

Cultivation and extraction

Isolation

Antibacterial assay

Part B. NMR data

Table SB1. NMR spectral data for Meroindenon (1) in DMSO- $d_{6}$

Table SB2. NMR spectral data for merochlorins E (2) and F (3) in DMSO- $d_{6}$.

Figure SB1. COSY and key HMBC correlations of merochlorin E (2)

Figure SB2. ${ }^{1} \mathrm{H}$ NMR spectrum of Meroindenon (1) in DMSO- $d_{6}$

Figure SB3. ${ }^{13} \mathrm{C}$ NMR Spectrum of Meroindenon (1) in DMSO- $d_{6} \ldots$

Figure SB4. COSY Spectrum of Meroindenon (1) in DMSO- $d_{6} \ldots$

Figure SB5. HSQC Spectrum of Meroindenon (1) in DMSO- $d_{6}$.....

Figure SB6. HMBC Spectrum of Meroindenon (1) in DMSO- $d_{6}$

Figure SB7. NOESY Spectrum of Meroindenon (1) in DMSO- $d_{6}$

Figure SB8. ${ }^{1} \mathrm{H}$ NMR Spectrum of Merochlorin E (2) in DMSO- $d_{6}$

Figure SB9. ${ }^{13} \mathrm{C}$ NMR Spectrum of Merochlorin E (2) in DMSO- $d_{6}$

Figure SB10. COSY Spectrum of Merochlorin E (2) in DMSO- $d_{6}$

Figure SB11. HSQC Spectrum of Merochlorin E (2) in DMSO- $d_{6}$

Figure SB12. HMBC Spectrum of Merochlorin E (2) in DMSO- $d_{6}$

Figure SB13. NOESY Spectrum of Merochlorin E (2) in DMSO- $d_{\sigma}$

Figure SB14. ${ }^{1} \mathrm{H}$ NMR Spectrum of Merochlorin F (3) in DMSO- $d_{6}$

Conformational search and CP3 analysis

Figure SC1. Experimental ECD spectra of $\mathbf{2}$ (cyan), and $\mathbf{3}$ (navy) . 
Table SC2. ECD calculation of $(9 R, 10 S)-\mathbf{2 b}$ model of merochlorin

Table SC3. The major conformers of merochlorins E (2) and F (3) identified by conformational searches in MMFF94 force field using the macromodel

Table SC4. Experimental (Exp.) and calculated (Cal.) chemical shift values (CS, $\delta)$ of merochlorins E (2) and F (3)

Figure SC2. Evaluation of similarity factors of ECD spectra of meroindenon by SpecDis

Figure SC3. Evaluation of similarity factors of ECD spectra of partial structure of merochlorins by SpecDis .

S30

Figure SC4. ECD calculation of full structure models of merochlorin E (2)

Figure SC5. ECD calculation of full structure models of merochlorin F (3) 


\section{Part A. General experimental procedures}

\section{General Experimental Procedures}

The optical rotations were acquired using a Kruss Optronic P-8000 polarimeter with a 5-cm cell. UV spectra were recorded in a Varian Cary UV-visible spectrophotometer with a path length of $1 \mathrm{~cm}$ and IR spectra were recorded on a Perkin-Elmer 1600 FT-IR spectrometer. CD spectra were recorded using an Applied Photophysics Chirascan-Plus circular dichroism spectrometer (Applied Photophysics Ltd., Leatherhead, Surrey, UK). ${ }^{1} \mathrm{H}$ and 2D NMR spectra data were recorded at 500 and $600 \mathrm{MHz}$ in DMSO- $d_{6}$ and $\mathrm{CDCl}_{3}$, solutions containing $\mathrm{Me}_{4} \mathrm{Si}$ as internal standard on Varian Inova spectrometers. ${ }^{13} \mathrm{C}$ NMR spectra were acquired at 125 or $150 \mathrm{MHz}$ on a Varian Inova spectrometer. High resolution ESI-TOF mass spectra were provided by The Scripps Research Institute, La Jolla, CA or by the mass spectrometry facility at the Department of Chemistry and Biochemistry at the University of California, San Diego, La Jolla, CA. Low resolution LC/MS data were measured using a Hewlett-Packard series 1100 LC/MS system with a reversed-phase $\mathrm{C}_{18}$ column (Phenomenex Luna, $4.6 \mathrm{~mm} \times 100 \mathrm{~mm}, 5 \mu \mathrm{m}$ ) at a flow rate of $0.7 \mathrm{~mL} / \mathrm{min}$.

\section{Collection and Phylogenetic Analysis of Strain CNH-189}

The marine-derived actinomycete, strain CNH-189, was isolated from a marine sediment sample collected near Oceanside, California. It was identified as a Streptomyces sp. based on 16S rRNA gene sequence analysis (accession number HQ214120).

\section{Cultivation and Extraction.}

The bacterium (strain CNH-189) was cultured in sixty $2.8 \mathrm{~L}$ Fernbach flasks each containing $1 \mathrm{~L}$ of a deionized water-based medium (M1: $10 \mathrm{~g} / \mathrm{L}$ glucose, $20 \mathrm{~g} / \mathrm{L}$ Grandma's molasses, $5 \mathrm{~g} / \mathrm{L}$ peptone, $2 \mathrm{~g} / \mathrm{L} \mathrm{CaCO} 3,40 \mathrm{mg} / \mathrm{L} \mathrm{Mg}\left(\mathrm{SO}_{4}\right) \cdot 4 \mathrm{H}_{2} \mathrm{O}, 200 \mathrm{mg} / \mathrm{L} \mathrm{KCl}, 200 \mathrm{mg} / \mathrm{L} \mathrm{KBr}$, and $\left.40 \mathrm{mg} / \mathrm{L} \mathrm{Fe}_{2}\left(\mathrm{SO}_{4}\right)_{3} \cdot 4 \mathrm{H}_{2} \mathrm{O}\right)$ at $27^{\circ} \mathrm{C}$. After 24 hour of cultivation, sterilized XAD7HP resin $(20 \mathrm{~g} / \mathrm{L})$ was added, and the culture was incubated for an additional 5 days at $27^{\circ} \mathrm{C}$. After culture in the presence of XAD7HP resin, the resin was collected on cheesecloth, washed with deionized water, and eluted with acetone. The acetone was removed under reduced pressure, and the resulting aqueous layer was extracted with ethyl acetate $(3 \times 500 \mathrm{~mL})$. The ethyl acetate-soluble fraction was dried in vacuo to yield $4.5 \mathrm{~g}$ of organic extract.

\section{Isolation of Meroindenon, Merochlorins $\mathbf{E}$ and $\mathbf{F}$.}

The organic extract $(4.5 \mathrm{~g})$ was fractionated by open column chromatography on silica gel $(25 \mathrm{~g})$, eluted with a step gradient of dichloromethane and methanol to afford seven fractions. The fraction (dichloromethane:methanol = 100:1) was purified by reversed-phase HPLC (Phenomenex Luna C-18 (2), $250 \times 100 \mathrm{~mm}, 2.0 \mathrm{~mL} / \mathrm{min}, 5 \mu \mathrm{m}, 100 \AA, \mathrm{UV}=254 \mathrm{~nm})$ using an isocratic solvent system from $80 \% \mathrm{CH}_{3} \mathrm{CN}$ to afford meroindenon $(\mathbf{1}, 4.6 \mathrm{mg})$. The fourth fraction was subjected on reversed-phase HPLC chromatographic separation (Phenomenex Luna C-18 (2), $250 \times 100 \mathrm{~mm}, 2.0 \mathrm{~mL} / \mathrm{min}, 5 \mu \mathrm{m}, 100$ $\AA, \mathrm{UV}=254 \mathrm{~nm})$ eluting with $82 \% \mathrm{CH}_{3} \mathrm{CN}$ in water to afford merochlorins $\mathrm{E}(2,5.3 \mathrm{mg})$, and $\mathrm{F}(\mathbf{3}, 4.5 \mathrm{mg})$.

Meroindenon (1): pale yellow oil; [ $\alpha]_{\mathrm{D}}^{21}+165\left(c\right.$ 0.68, MeOH); UV (MeOH) $\lambda_{\max }(\log \varepsilon) 210(4.6), 240(4.5), 296(4.1), 330(3.8) \mathrm{nm} ; \mathrm{IR}(\mathrm{KBr}) v_{\max }$ 2348, 1680, 1606, $1186 \mathrm{~cm}^{-1} ;{ }^{1} \mathrm{H}$ and 2D-NMR (300 MHz, DMSO- $d_{6}$ ), see Table 1; HR-ESI-MS [M+H] ${ }^{+} \mathrm{m} / z$ 397.2366 (calcd for $\mathrm{C}_{25} \mathrm{H}_{33} \mathrm{O}_{4}, 397.2379$ ). 
Merochlorin E (2): pale yellow oil; $[\alpha]_{\mathrm{D}}^{21}+187\left(c\right.$ 0.64, MeOH); UV (MeOH) $\lambda_{\max }(\log \varepsilon) 224$ (4.6), 239 (4.7), 296 (4.3), $334(4.3) \mathrm{nm}$; IR (KBr) $v_{\max }$ $3387,2929,2350,1700,1629,1368,1270,1168,858,753 \mathrm{~cm}^{-1} ;{ }^{1} \mathrm{H}$ and 2D-NMR (500 MHz, DMSO- $\left.d_{6}\right)$, see Table $3 ; \mathrm{HR}-\mathrm{ESI}-\mathrm{MS}[\mathrm{M}+\mathrm{H}]^{+} \mathrm{m} / z$ 461.2096 (calcd for $\mathrm{C}_{26} \mathrm{H}_{34}{ }^{35} \mathrm{ClO}_{5}, 461.2095$ ).

Merochlorin F (3): pale yellow oil; [ $\alpha]_{\mathrm{D}}^{21}+80\left(c\right.$ 0.57, MeOH); UV (MeOH) $\lambda_{\max }(\log \varepsilon) 224$ (4.6), 239 (4.7), $296(4.3), 334(4.3) \mathrm{nm}$; IR (KBr) $v_{\max }$ $3393,2927,2347,1968,1629,1369,1271,1168,858,754 \mathrm{~cm}^{-1} ;{ }^{1} \mathrm{H}$ and 2D-NMR $\left(400 \mathrm{MHz}\right.$, DMSO- $\left.d_{6}\right)$, see Table 2; HR-ESI-MS [M+H] ${ }^{+} \mathrm{m} / z$ 461.2094 (calcd for $\mathrm{C}_{26} \mathrm{H}_{34}{ }^{35} \mathrm{ClO}_{5}, 461.2095$ ).

\section{Antibacterial Assay.}

Antibacterial susceptibility was tested against three Gram-positive bacteria (Bacillus subtilis ATCC 6633, Kocuria rhizophila ATCC 9341, and Staphylococcus aureus ATCC 6538P) and three Gram-negative bacteria (Escherichia coli ATCC 11775, Salmonella typhimurium ATCC 14028, and Klebsiella pneumoniae ATCC 4352). These bacteria were grown in Mueller-Hinton broth at $37^{\circ} \mathrm{C}$ and $225 \mathrm{rpm}$ for $24 \mathrm{~h}$. Compounds 1-4 and positive controls were dissolved in DMSO, and $100 \mu \mathrm{L}$ was dispensed to 96 -well plates starting at $128 \mu \mathrm{g} / \mathrm{mL}$ concentration. Compounds 1-4 and positive controls were serially diluted, and Mueller-Hinton broth was added to a final concentration of $0.5 \%$ McFarland standard. The 96 -well microtiter plates were cultivated for $24 \mathrm{~h}$ at $37^{\circ} \mathrm{C}$. Minimal inhibitory concentration (MIC) values were the lowest positive control concentration that inhibited visible growth of bacteria. 


\section{Part B. NMR data}

Table SB1. NMR Spectral Data for Meroindenone (1) (DMSO- $\left.d_{\delta}\right)^{\mathrm{a}}$

\begin{tabular}{|c|c|c|c|c|}
\hline No. & $\delta_{\mathrm{C}}$, mult. $^{\mathrm{b}}$ & $\delta_{\mathrm{H}}(J$ in $\mathrm{Hz})$ & COSY & HMBC \\
\hline 1 & $200.0, \mathrm{qC}$ & & & \\
\hline 2 & 120.2, qC & & & \\
\hline 3 & 158.1, qC & & & \\
\hline 4 & $110.1, \mathrm{CH}$ & $6.52, \mathrm{~d}(2.0)$ & 6 & $C-2,3,6$ \\
\hline 5 & 166.3, qC & & & \\
\hline 6 & $100.7, \mathrm{CH}$ & $6.48, \mathrm{~d}(2.0)$ & 4 & C- 2,4 \\
\hline 7 & $144.9, \mathrm{qC}$ & & & \\
\hline 8 & $204.8, \mathrm{qC}$ & & & \\
\hline 9 & $54.9, \mathrm{qC}$ & & & \\
\hline 10 & $38.8, \mathrm{CH}_{2}$ & 2.37, d (14.0), 2.34 & & $\mathrm{C}-1,8,9,11,12,25$ \\
\hline 11 & $128.0, \mathrm{qC}$ & & & \\
\hline 12 & $31.5, \mathrm{CH}_{2}$ & $2.34, \mathrm{~m}$ & 13 & C- $10,11,13,14,22$ \\
\hline 13 & $123.3, \mathrm{CH}$ & $4.66, \mathrm{t}(6.5)$ & 12 & C-11, 12, 15, 24 \\
\hline 14 & $134.9, \mathrm{qC}$ & & & \\
\hline 15 & $40.0, \mathrm{CH}_{2}$ & $1.83, \mathrm{~m}$ & 16 & C- $13,14,16,17,24$ \\
\hline 16 & 26.6, $\mathrm{CH}_{2}$ & $1.93, \mathrm{~m}$ & 15,17 & C- $14,15,17,18$ \\
\hline 17 & $124.8, \mathrm{CH}$ & $4.97, \mathrm{t}(6.5)$ & 16 & $\mathrm{C}-15,19,19,20$ \\
\hline 18 & $131.3, \mathrm{qC}$ & & & \\
\hline 19 & $18.3, \mathrm{CH}_{3}$ & $1.50, \mathrm{~s}$ & & $\mathrm{C}-17,18,20$ \\
\hline 20 & $26.0, \mathrm{CH}_{3}$ & $1.59, \mathrm{~s}$ & & C-17, 18, 19 \\
\hline 21 & $21.7, \mathrm{CH}_{3}$ & $1.54, \mathrm{~s}$ & & C- $11,22,23$ \\
\hline 22 & $129.6, \mathrm{qC}$ & & & \\
\hline 23 & $20.6, \mathrm{CH}_{3}$ & $1.42, \mathrm{~s}$ & & $\mathrm{C}-11,21,22$ \\
\hline 24 & $16.5, \mathrm{CH}_{3}$ & $1.47, \mathrm{~s}$ & & $\mathrm{C}-13,14,15$ \\
\hline 25 & $20.5, \mathrm{CH}_{3}$ & $1.05, \mathrm{~s}$ & & $\mathrm{C}-1,8,9,10$ \\
\hline
\end{tabular}

a $500 \mathrm{MHz}$ for ${ }^{1} \mathrm{H}$ NMR and $75 \mathrm{MHz}$ for ${ }^{13} \mathrm{C}$ NMR. ${ }^{\mathrm{b}}$ Numbers of attached protons were determined by analysis of 2D spectra. 
Table SB2. NMR Spectral Data for Merochlorins E (2) and F (3) (DMSO- $\left.d_{6}\right)^{\mathrm{a}}$

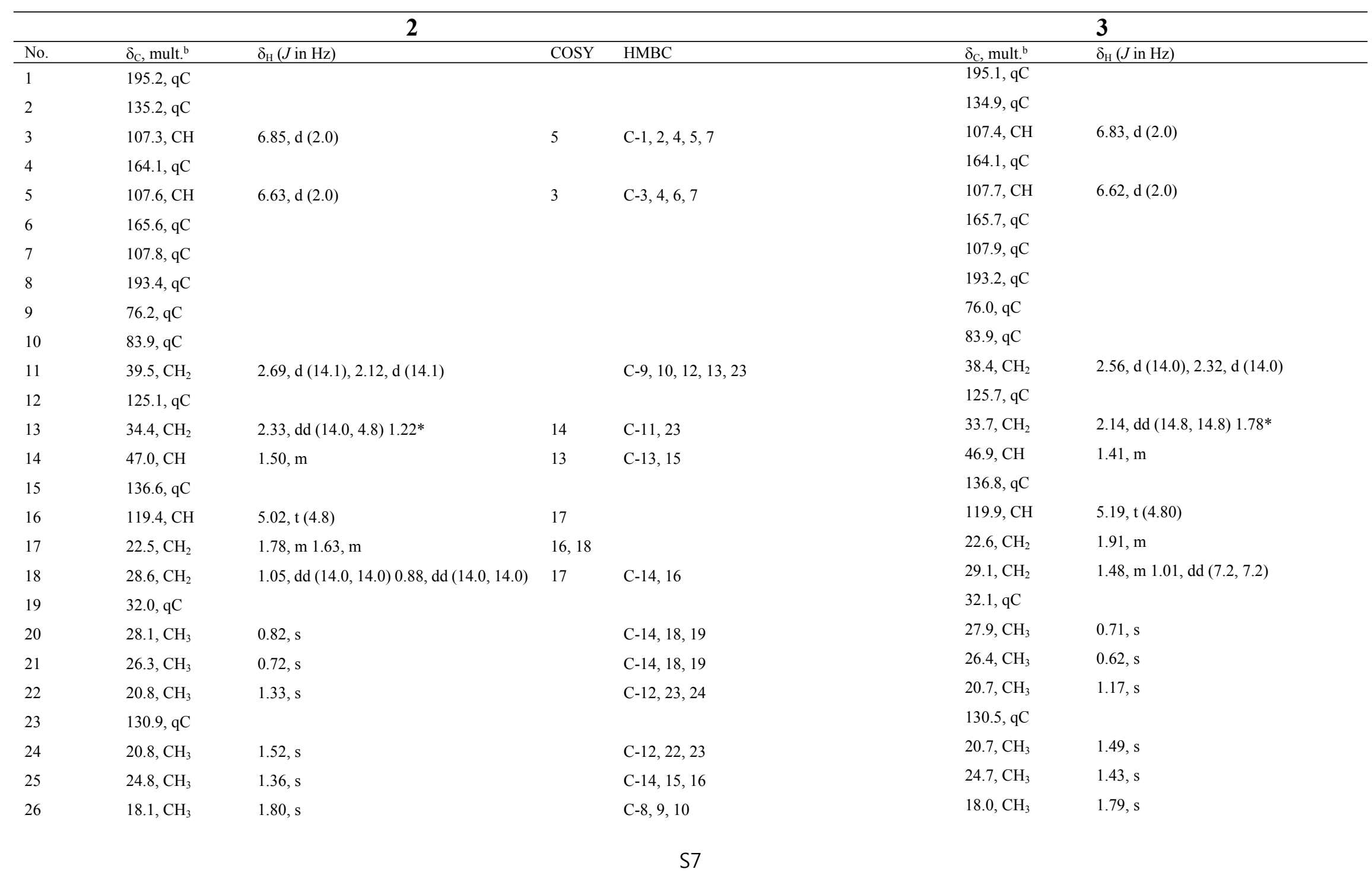



$\mathrm{C}-1,9,10,11$

${ }^{\mathrm{a}} 500 \mathrm{MHz}$ for ${ }^{1} \mathrm{H}$ NMR and $125 \mathrm{MHz}$ for ${ }^{13} \mathrm{C}$ NMR. ${ }^{\mathrm{b}}$ Numbers of attached protons were determined by analysis of $2 \mathrm{D}$ spectra. 
Figure SB1. COSY and key HMBC correlations of merochlorin E (2)

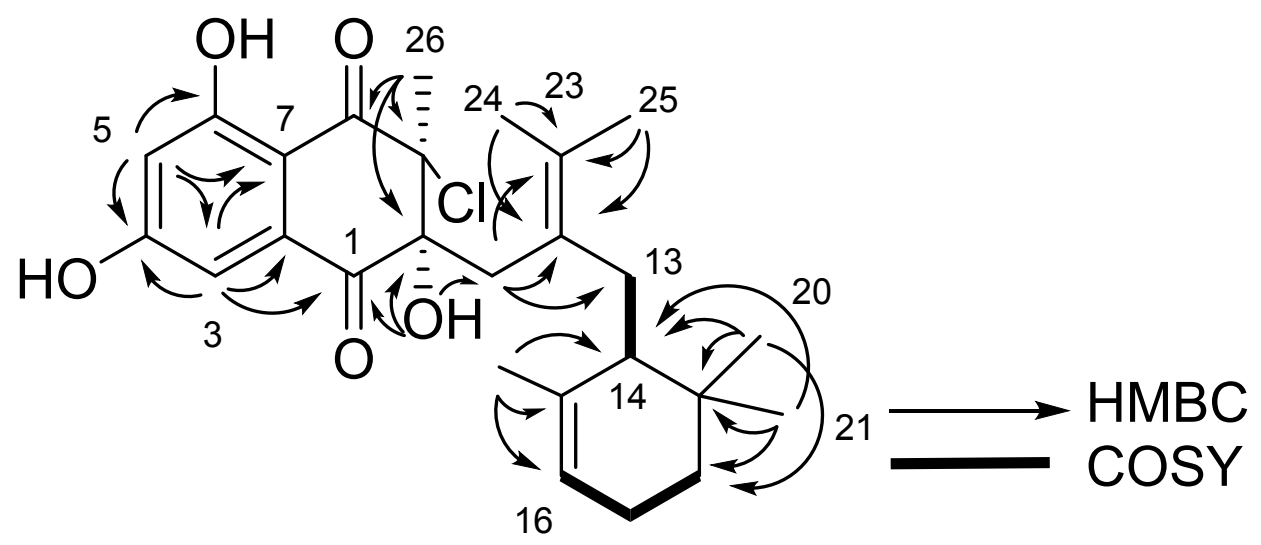


Figure SB2. ${ }^{1} \mathrm{H}$ NMR Spectrum of Meroindenon (1) in DMSO- $d_{6}$
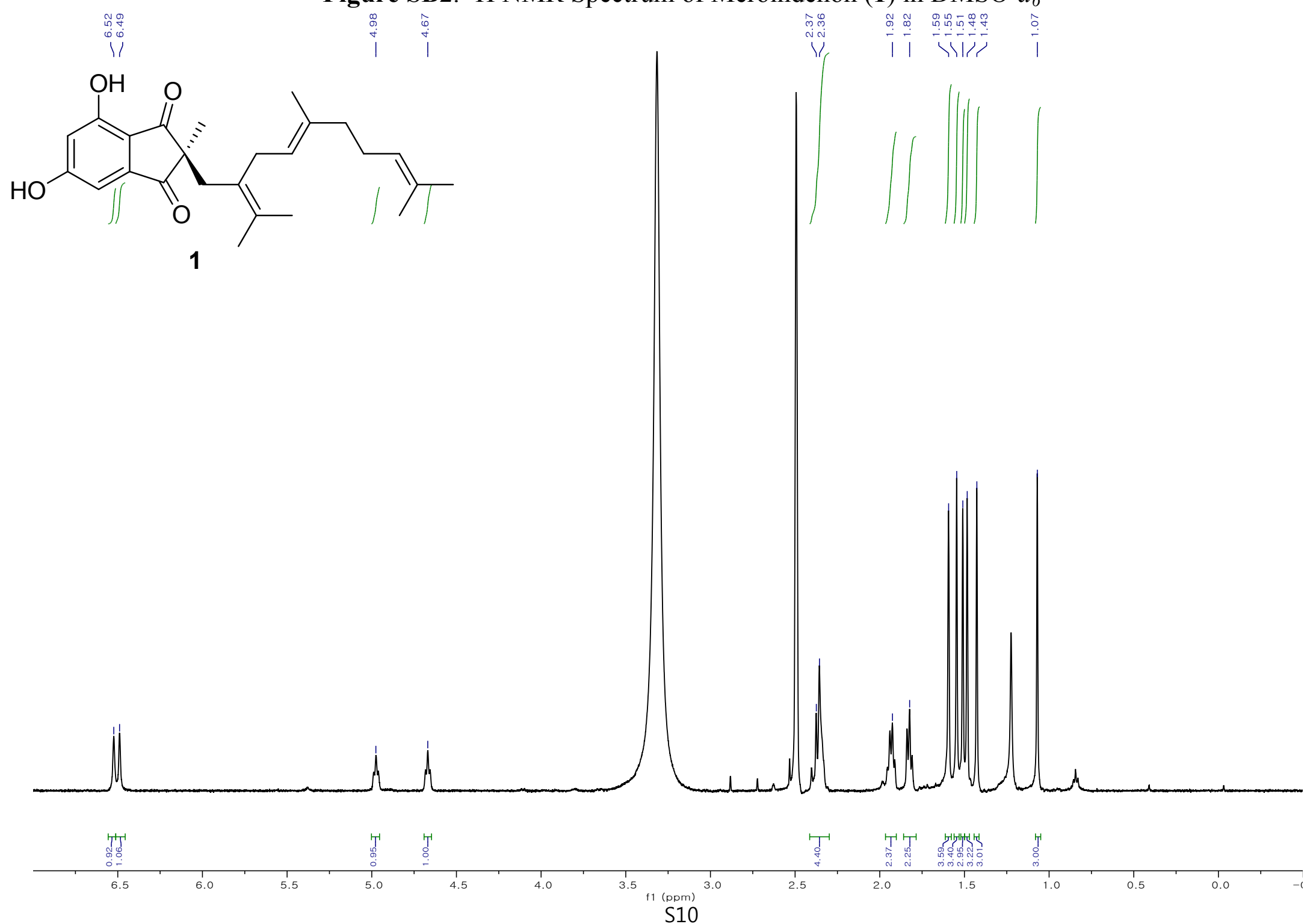

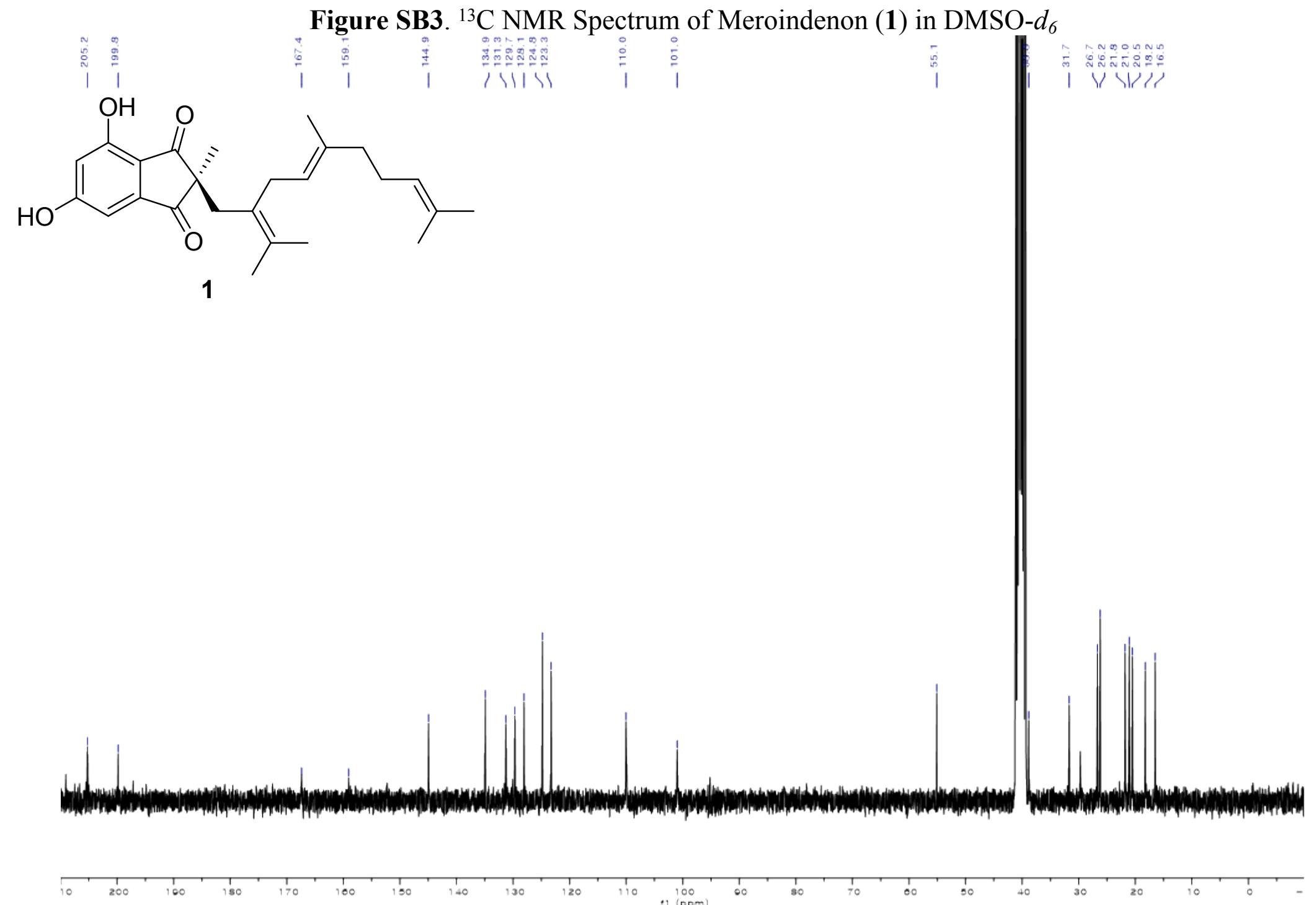
Figure SB4. COSY Spectrum of Meroindenon (1) in DMSO- $d_{6}$

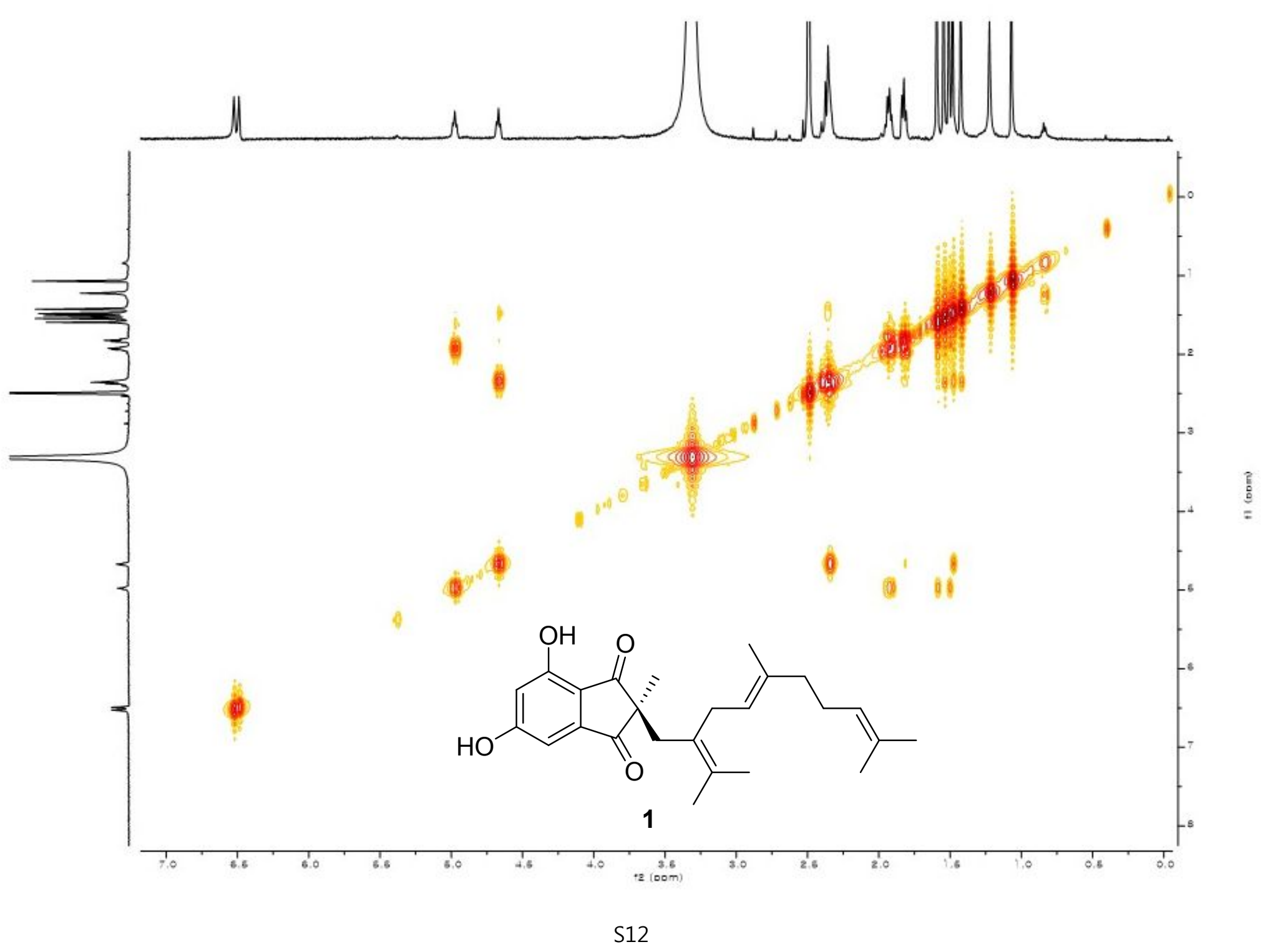


Figure SB5. HSQC Spectrum of Meroindenon (1) in DMSO- $d_{6}$

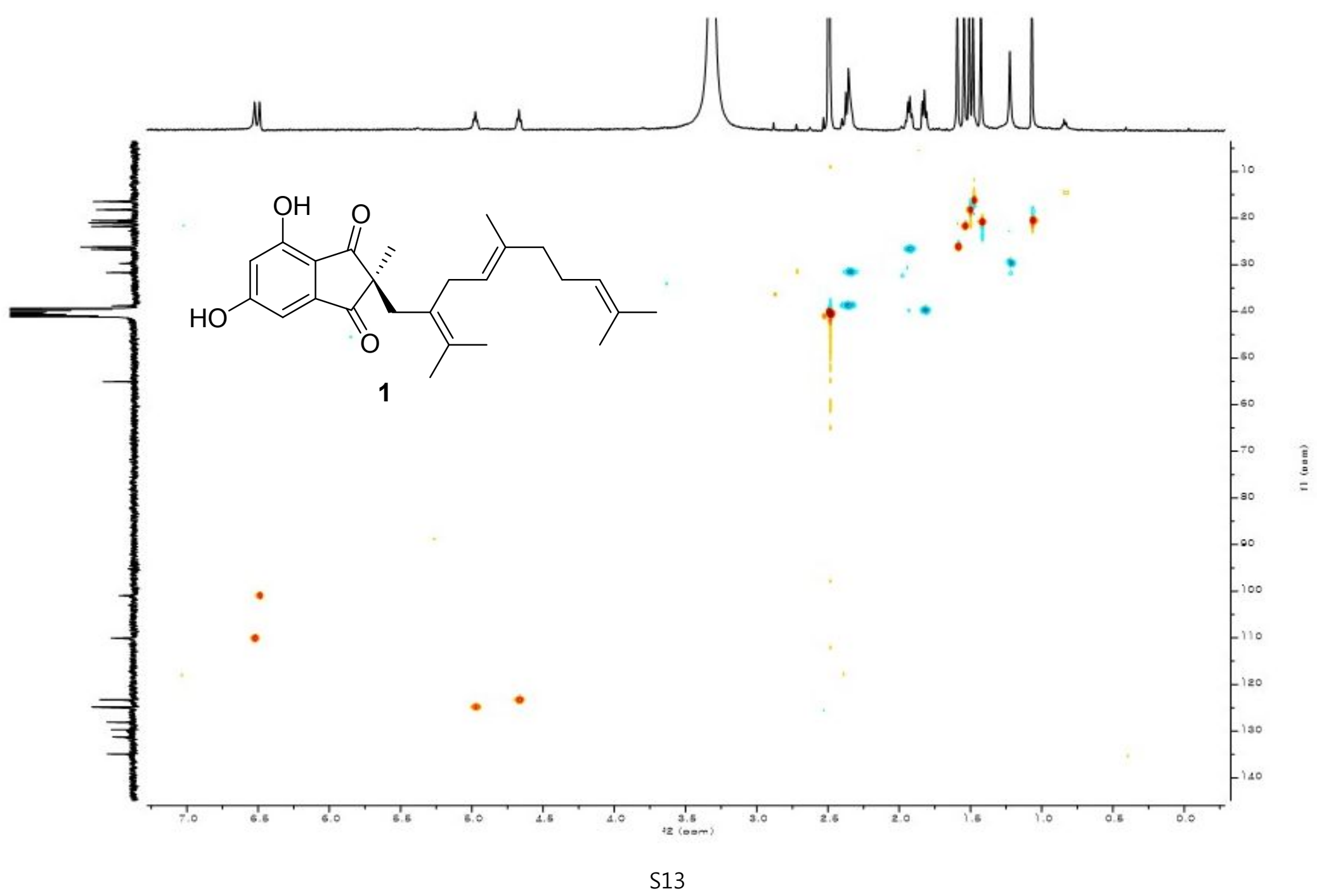


Figure SB6. HMBC Spectrum of Meroindenon (1) in DMSO- $d_{6}$

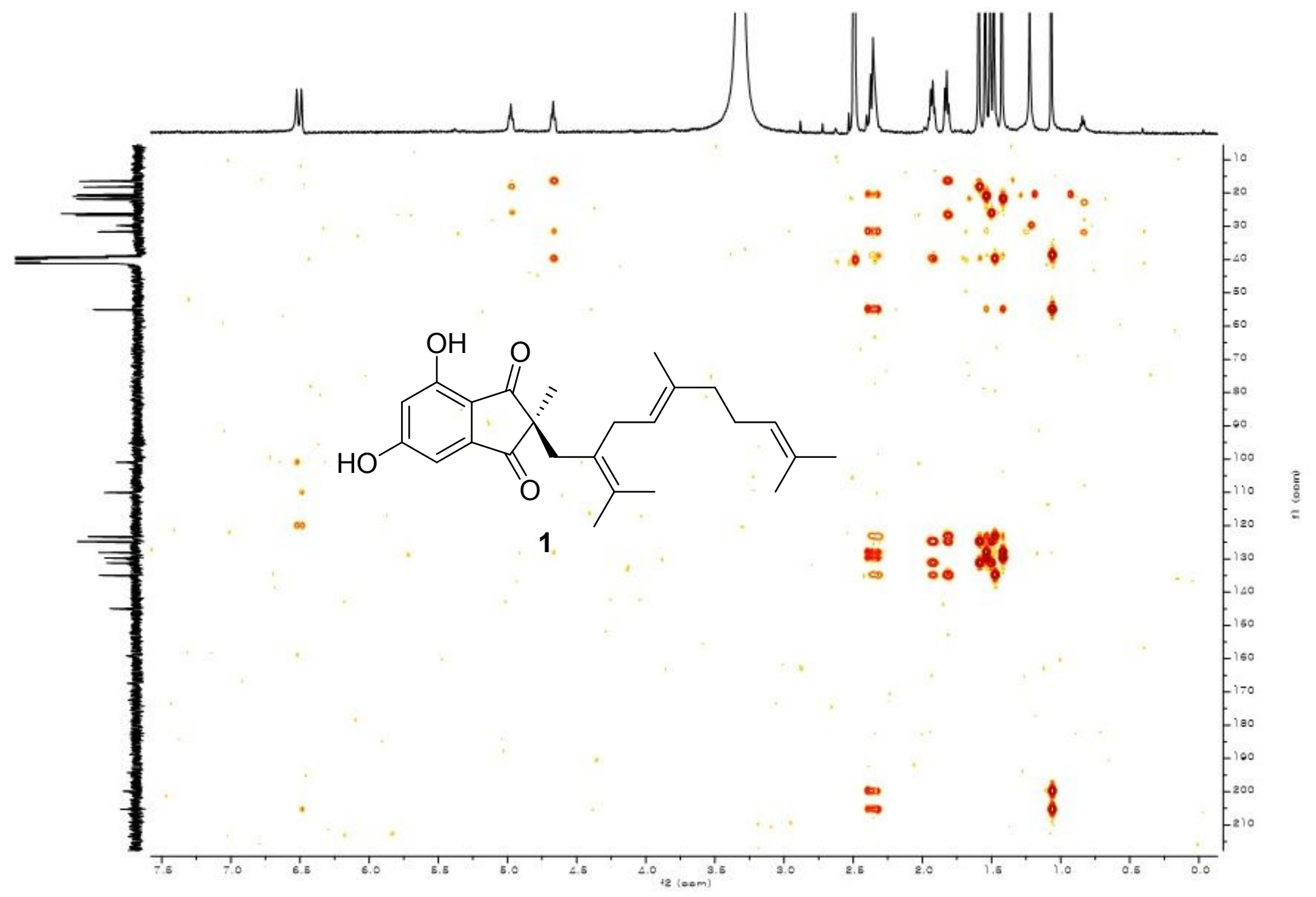




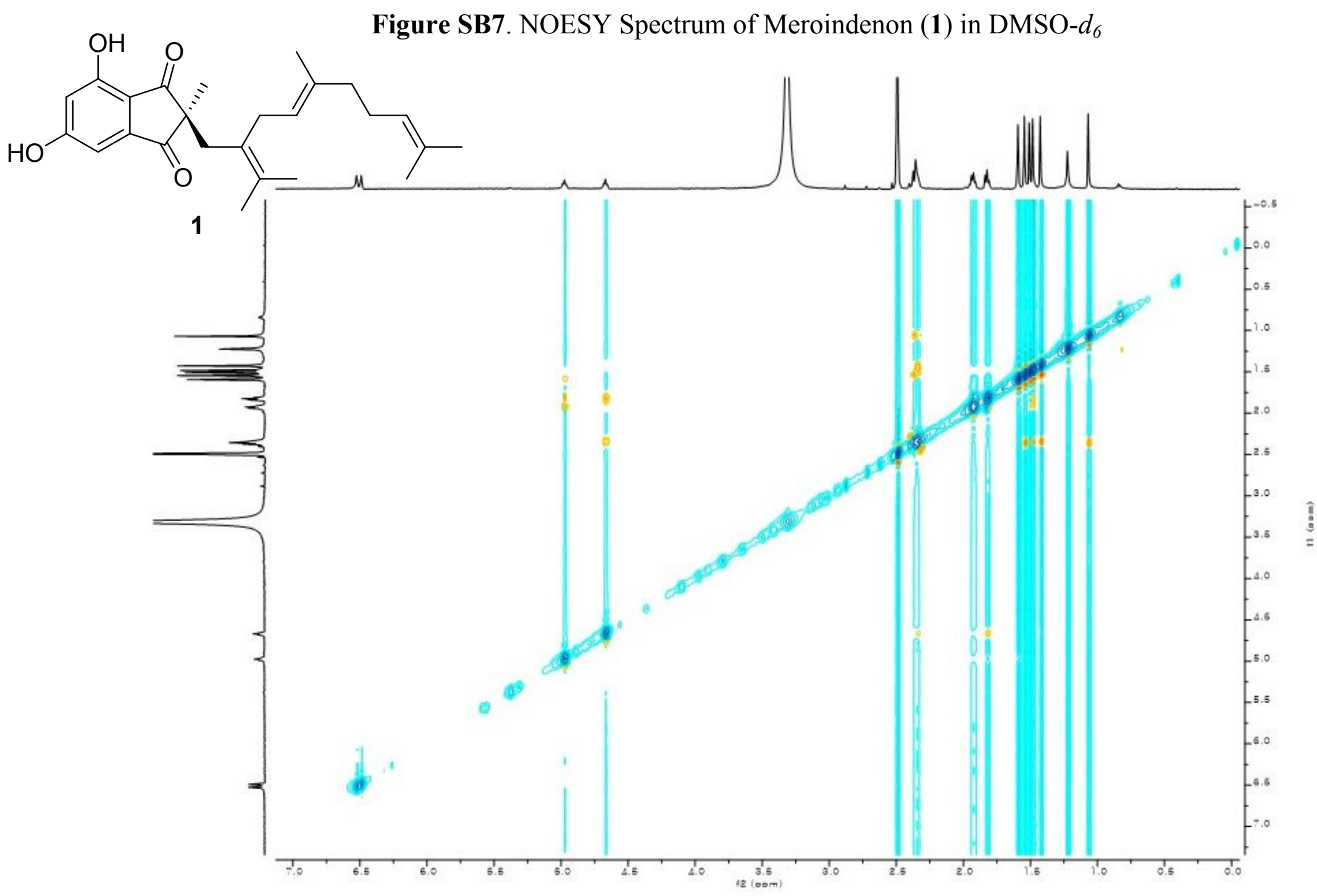


Figure SB8. ${ }^{1} \mathrm{H}$ NMR Spectrum of Merochlorin E (2) in DMSO- $d_{6}$

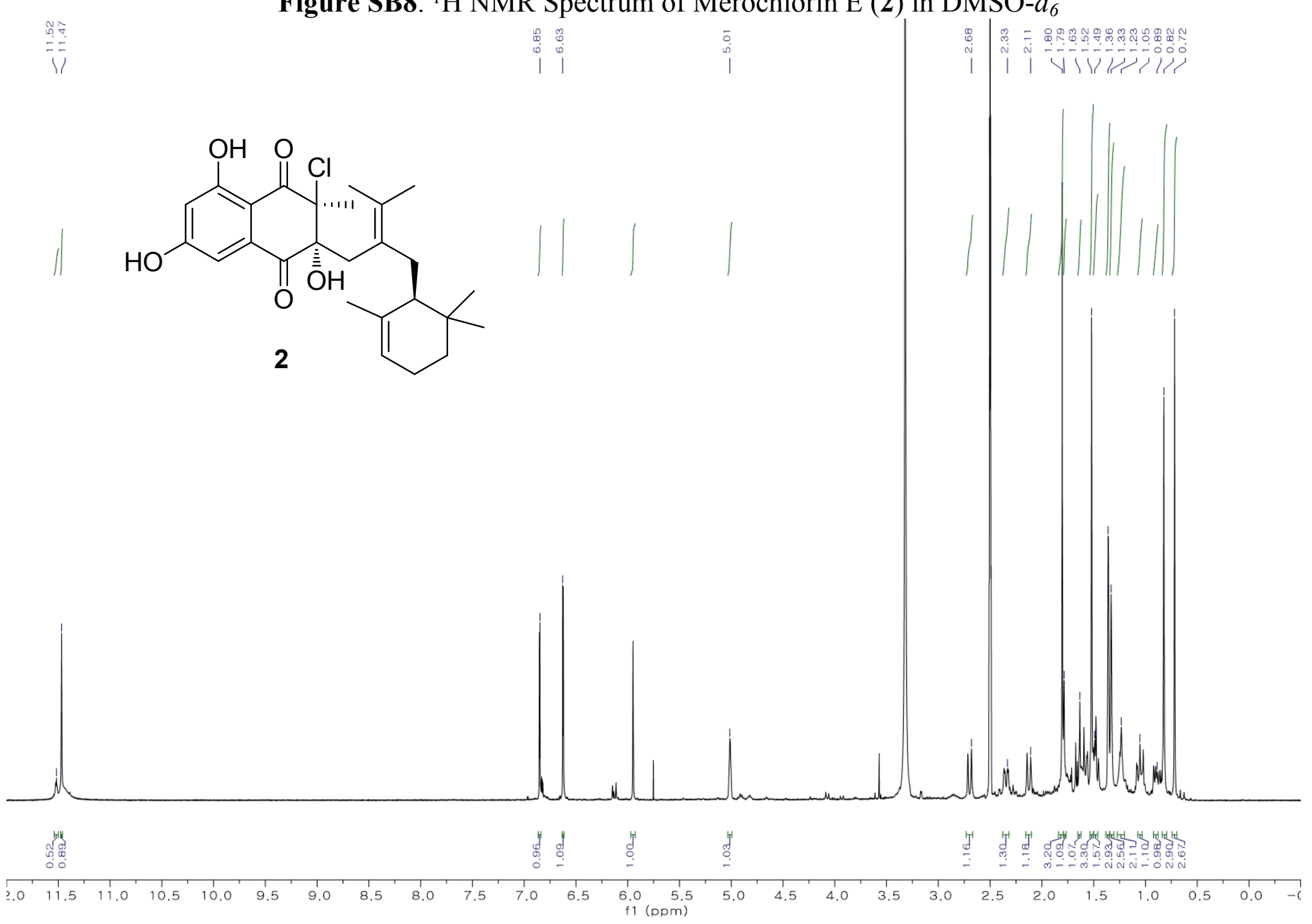


Figure SB9. ${ }^{13} \mathrm{C}$ NMR Spectrum of Merochlorin E (2) in DMSO- $d_{6}$

11

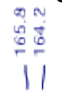

11
11

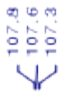

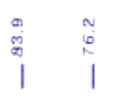

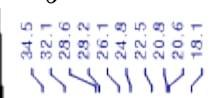
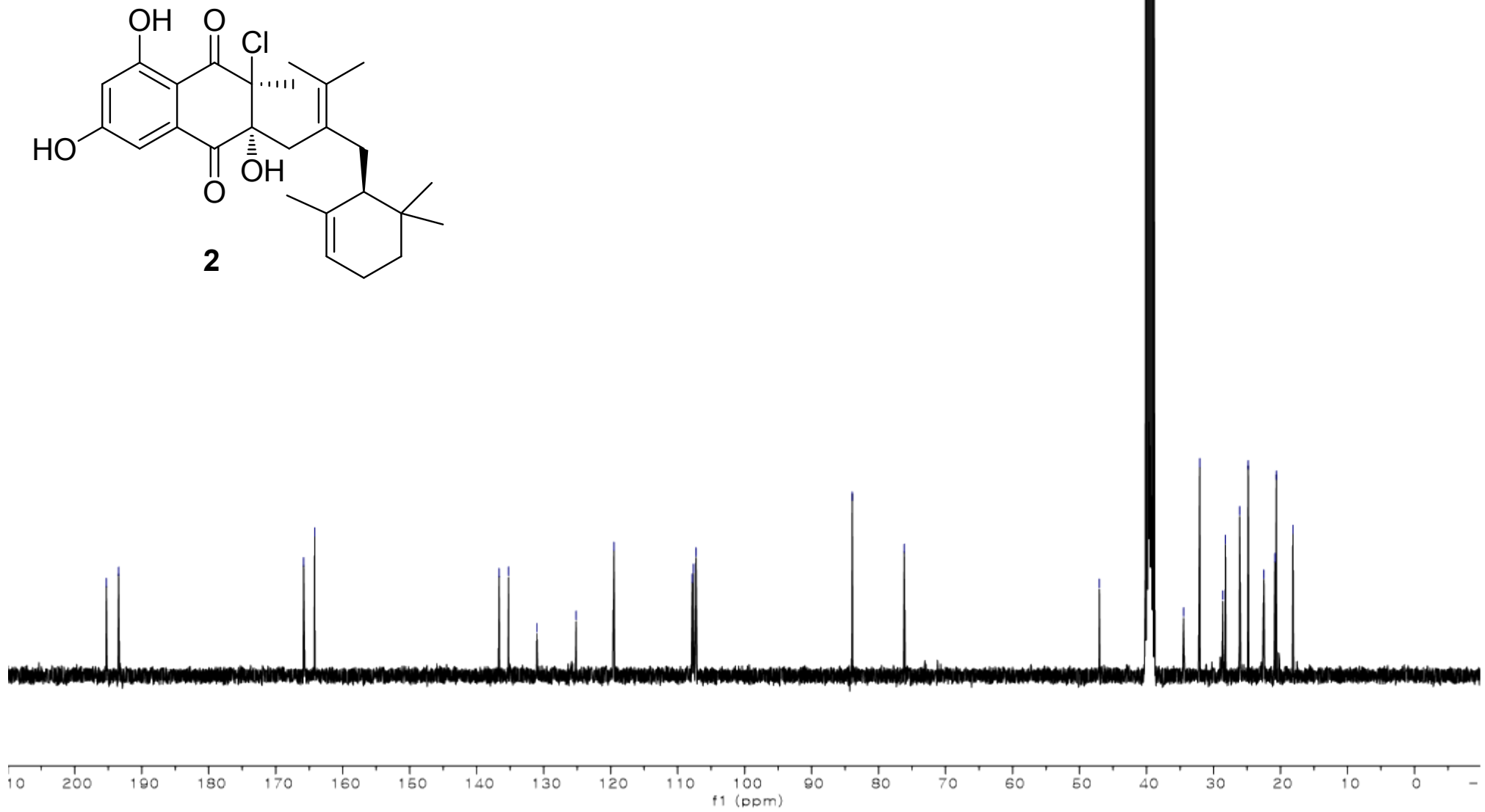

S17 
Figure SB10. COSY Spectrum of Merochlorin E (2) in DMSO- $d_{6}$

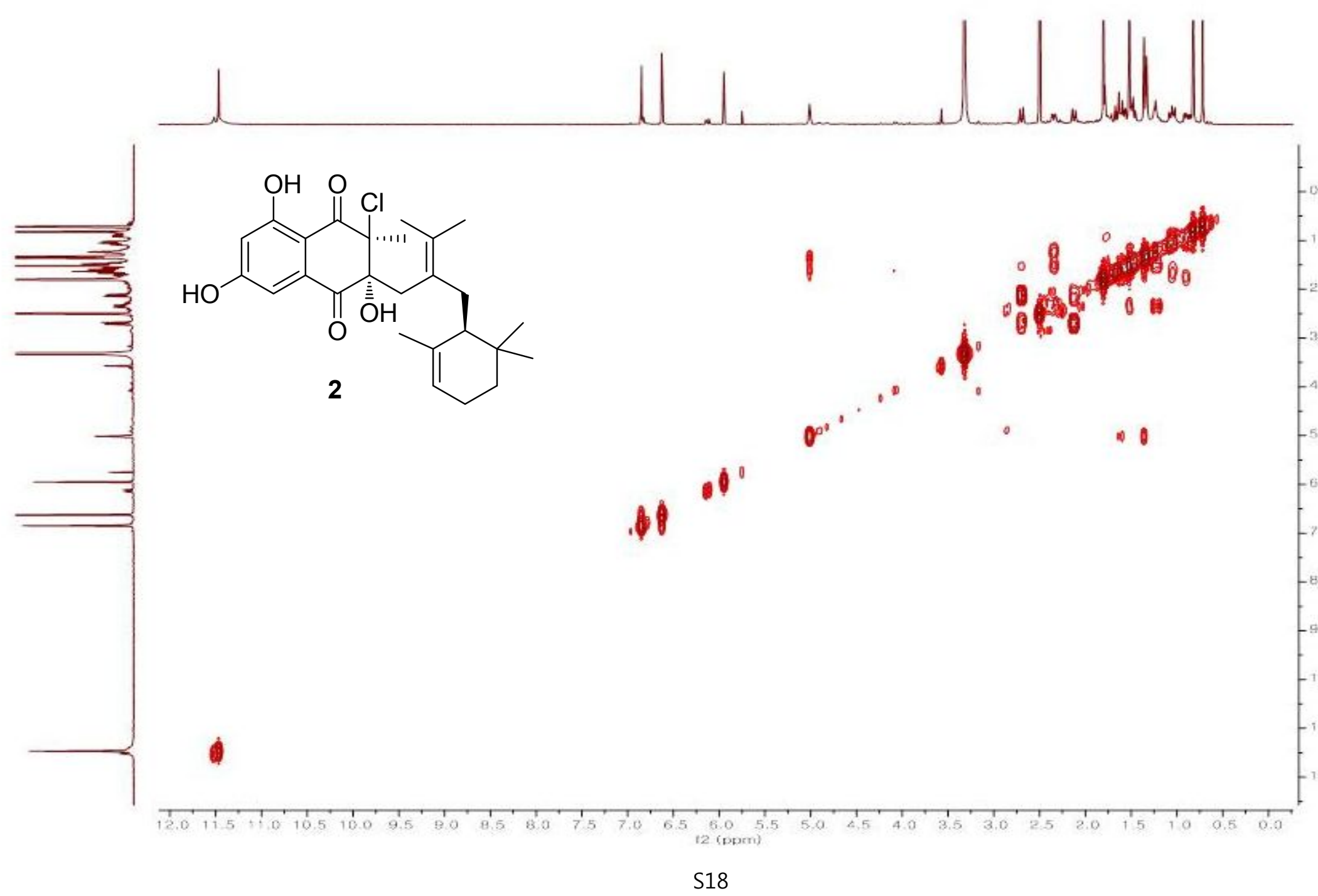


Figure SB11. HSQC Spectrum of Merochlorin E (2) in DMSO- $d_{6}$

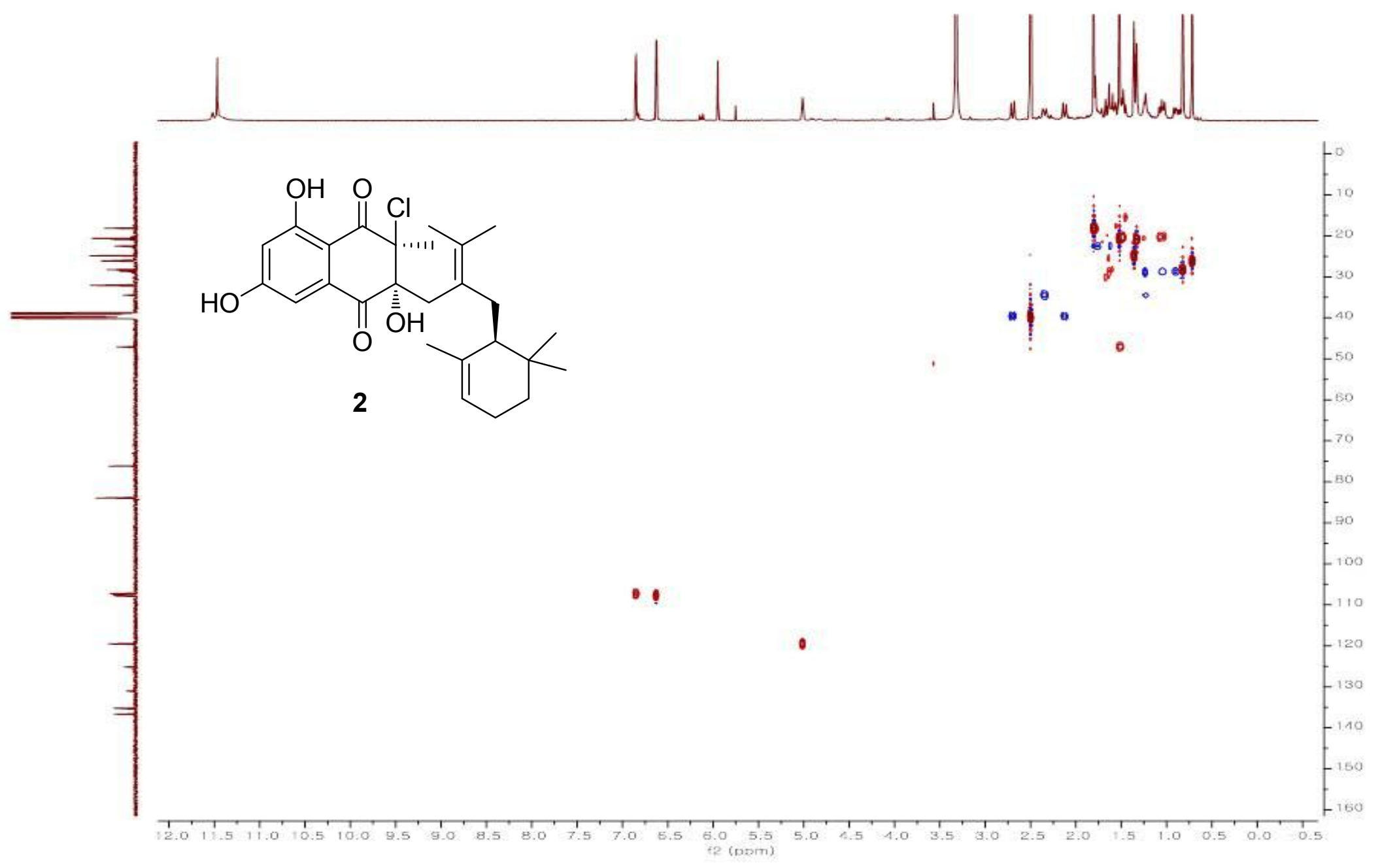


Figure SB12. HMBC Spectrum of Merochlorin E (2) in DMSO- $d_{6}$

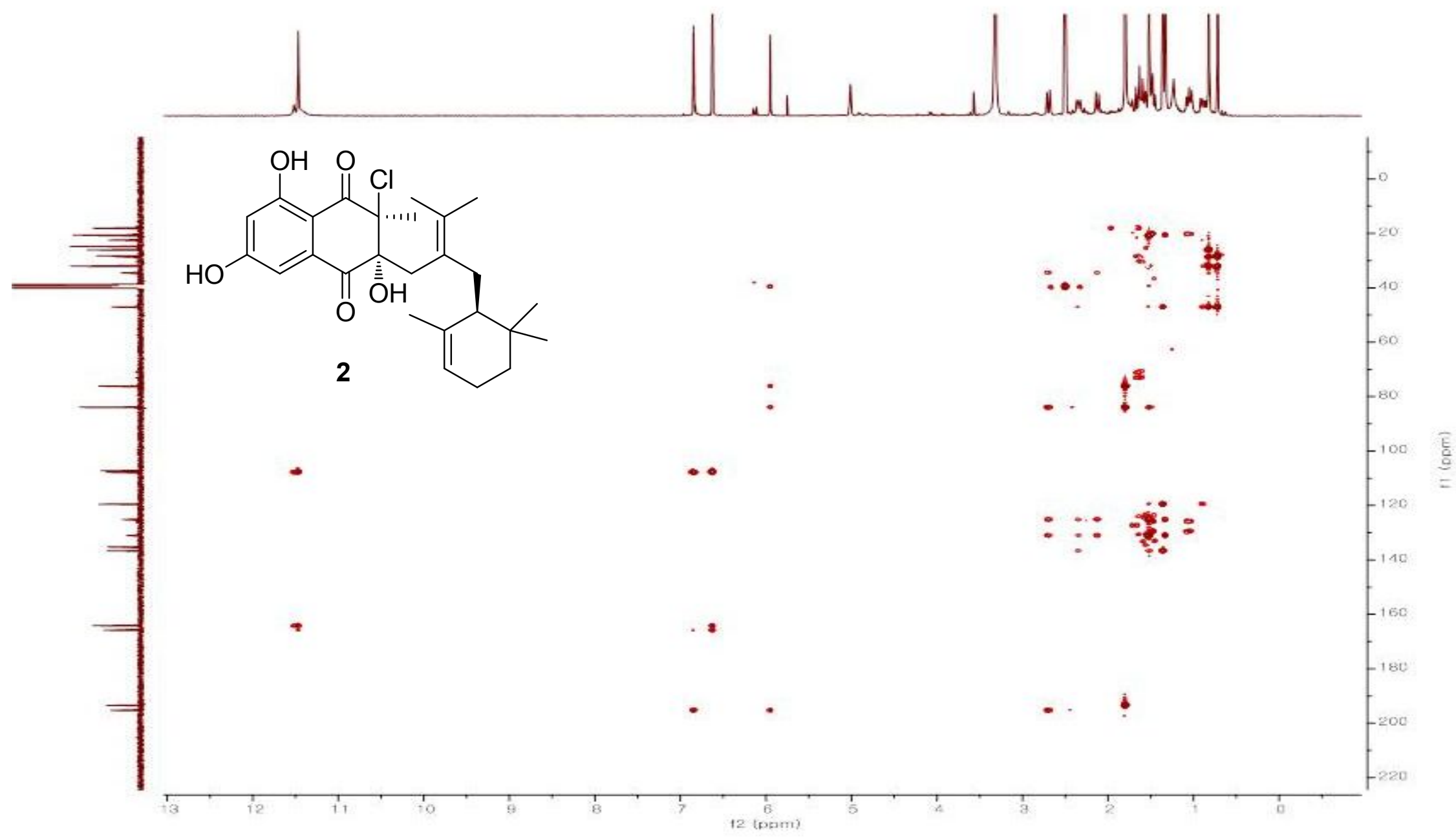


Figure SB13. NOESY Spectrum of Merochlorin E (2) in DMSO- $d_{6}$

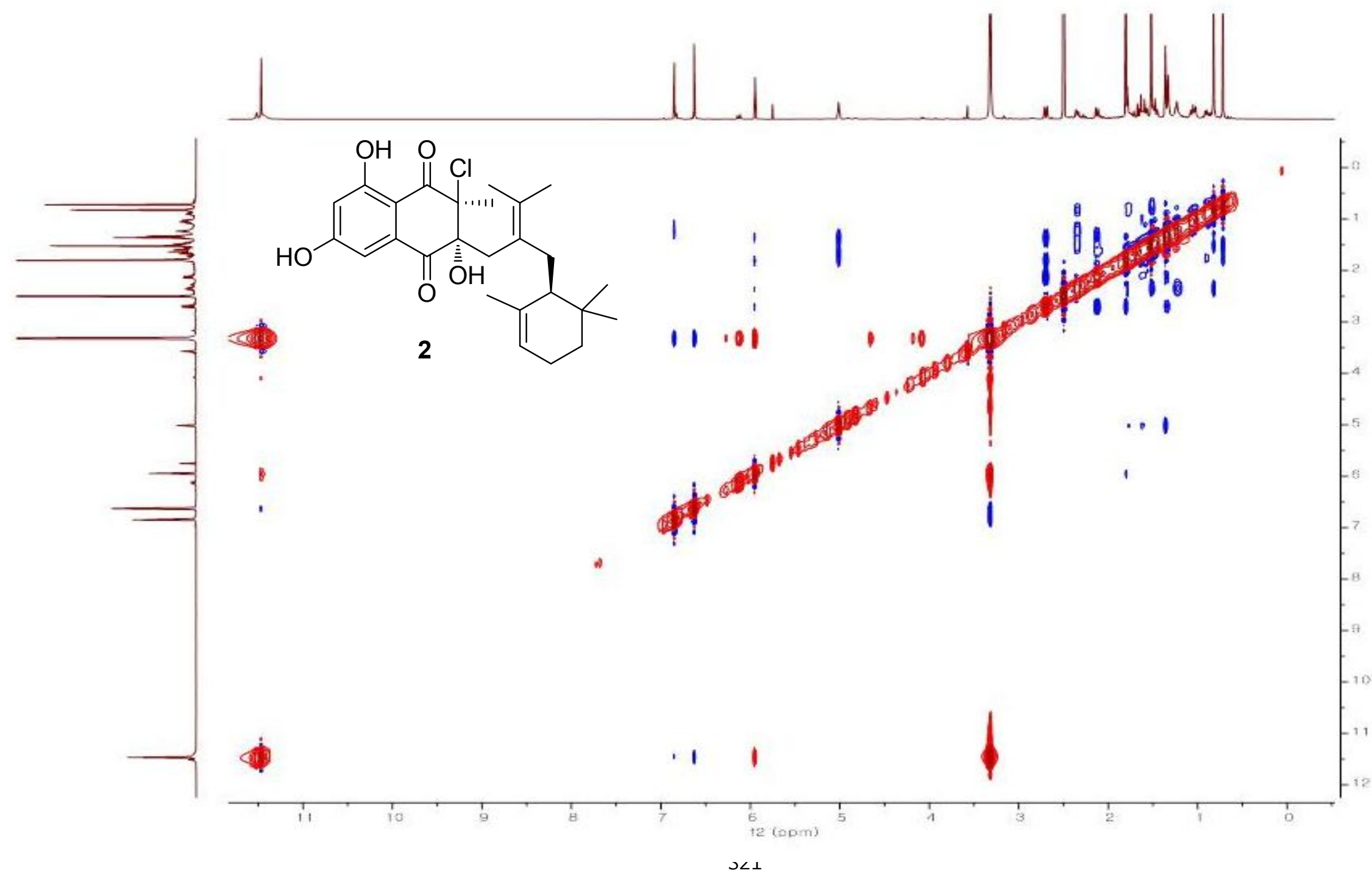


Figure SB14. ${ }^{1} \mathrm{H}$ NMR Spectrum of Merochlorin F (3) in DMSO- $d_{6}$

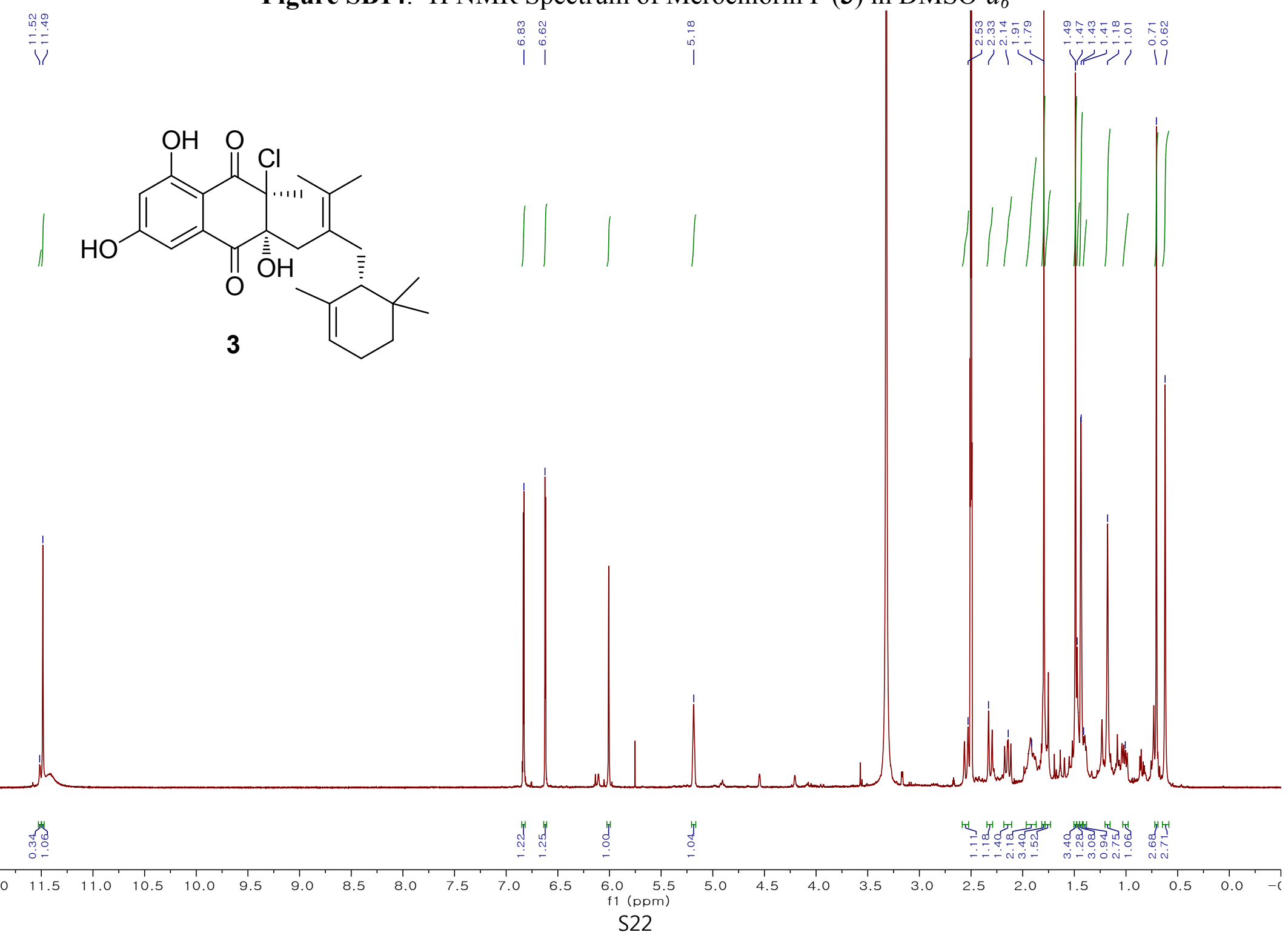


Figure SB15. ${ }^{13} \mathrm{C}$ NMR Spectrum of Merochlorin F (3) in DMSO- $d_{6}$
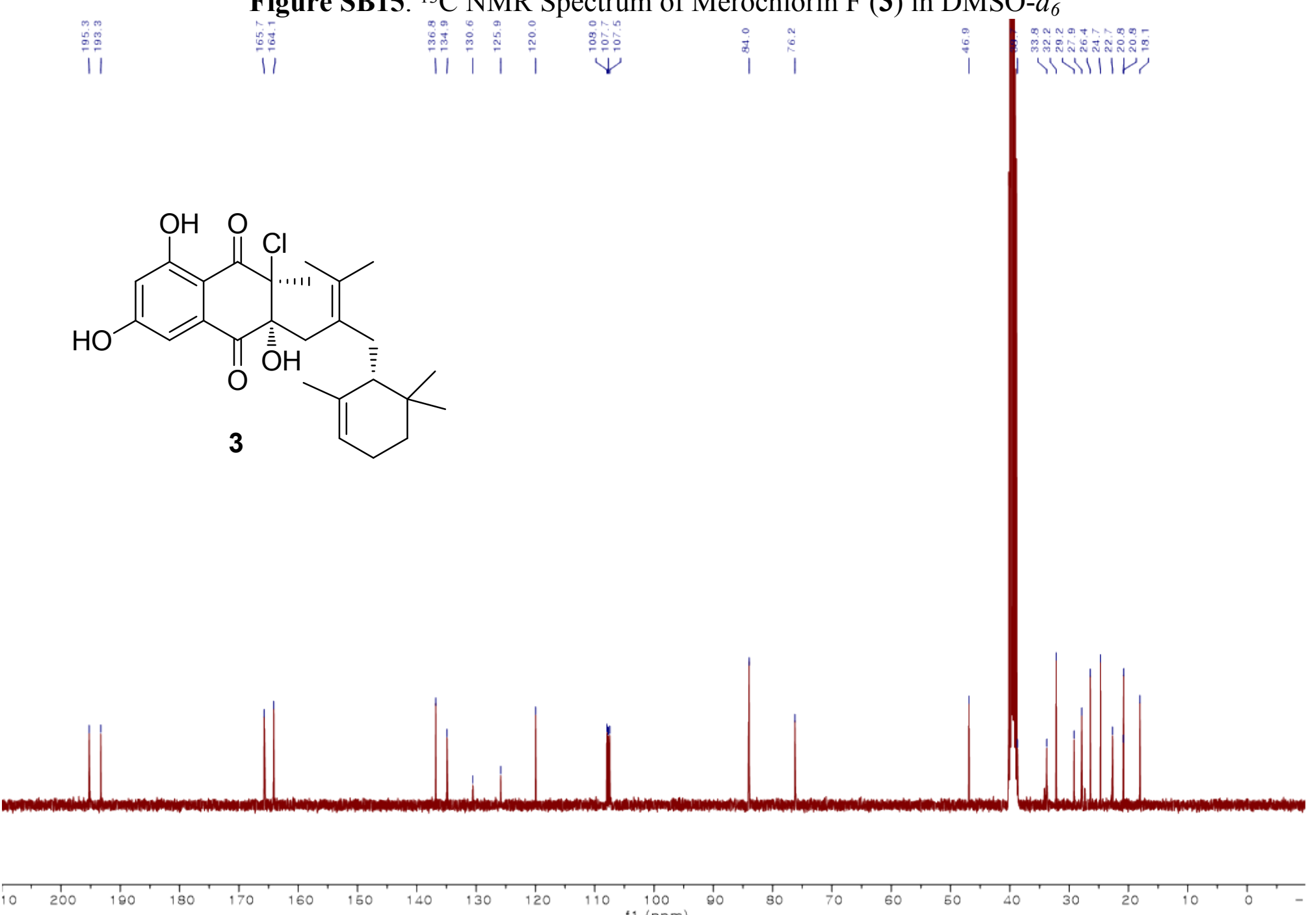


\section{Part C. DFT and ECD}

\section{DFT modeling and ECD calculations}

The truncated structure was used for calculating ECD spectra, assuming that the CD effect of the terminal 6-membered ring is limited. The energyminimized isomer structures were generated by Avogadro 1.2.0. Energy minimization of the two isomer structures was performed by Turbomole X 4.3.2. The ground state geometry optimization was calculated by TD-DFT (time dependent density functional theory) at the B3LYP/def-SV(P) level for all atoms. The calculated ECD spectra corresponding to optimized structures were calculated using DFT at the functional B3LYP/DFT level and the def$\mathrm{SV}(\mathrm{P})$ basis set. The ECD spectra were simulated by overlapping each transition, where $\sigma$ is the width of the band at $1 / e$ height. $\Delta E_{i}$ is the excitation energies and $R_{i}$ is rotatory strengths for transition $i$. In this calculation, the $\sigma$ value was at $0.10 \mathrm{eV}$. The observed ECD spectrum of 2 showed positive cotton effects at 214 and $332 \mathrm{~nm}$ and a negative cotton effect at $250 \mathrm{~nm}$. Comparing with the calculated spectra of the two isomers (2a and $\mathbf{2 b})$ with the measured ECD spectrum, the $9 S$ and $10 R$ configurations were clearly deduced.

$$
\Delta \epsilon(E)=\frac{1}{2.297 \times 10^{-39} \sqrt{2 \pi \sigma}} \sum_{i}^{A} \Delta E_{i} R_{i} e^{\left[-\left(E-\Delta E_{i}\right)^{2} /(2 \sigma)^{2}\right]}
$$

\section{Conformational search and CP3 analysis}

Conformational search of the merochlorins was performed by MacroModel with the Merck Molecular Force Field (gas phase), a $10 \mathrm{~kJ} / \mathrm{mol}$ upper energy limit, and a $0.001 \mathrm{~kJ}(\mathrm{~mol} \AA)^{-1}$ convergence threshold on the rms gradient to minimize computational complexity and expense. Six conformers were obtained for the $14 R$ diastereomer and 12 conformers for the $14 S$ model under the $10 \mathrm{~kJ} / \mathrm{mol}$ limit. The Boltzmann population of each conformer was calculated. Ground state geometry optimization of each conformer was carried out by density functional theory (DFT) modeling and TurbomoleX 4.3.2. The basis set for the calculation was def-SV(P) for all atoms and the level of theory was B3-LYP at the functional level in the gas phase. The calculated ${ }^{1} \mathrm{H}$ and ${ }^{13} \mathrm{C}$ chemical shift values were averaged by the Boltzmann population. Comparing with these Boltzmann averaged chemical shifts and the experimental chemical shifts, the CP3 analyses proposed the $14 R$ configuration of 2 and $14 S$ of 3 with $95.0 \%$ probability. 
Figure SC1. Experimental ECD spectra of $\mathbf{2}$ (cyan), and $\mathbf{3}$ (navy)

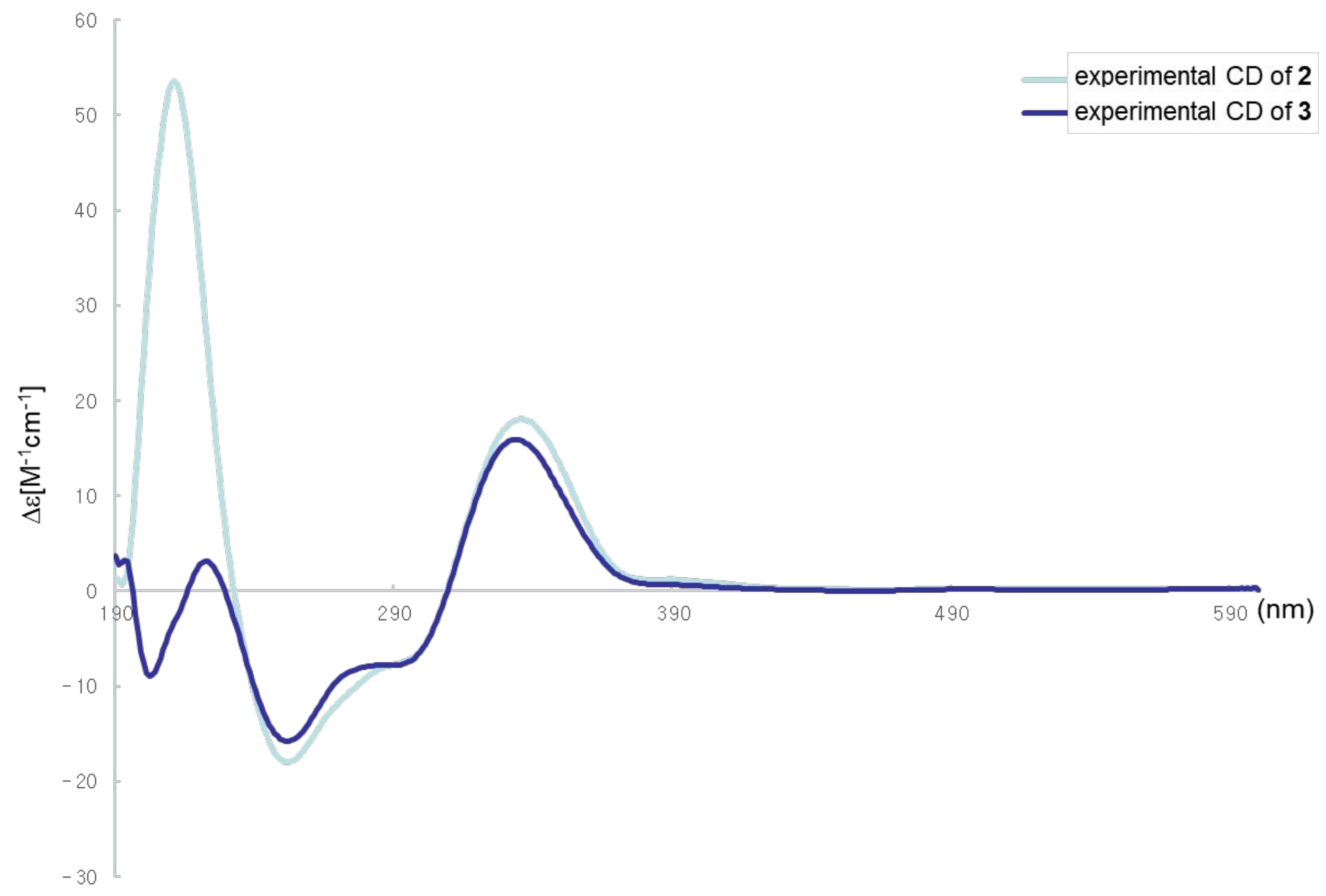


Table SC1. ECD calculation of $(9 S, 10 R)$-2a model of merochlorin

\begin{tabular}{lll} 
total energy & $=$ & -1493.96099319056 \\
\hdashline------ & 1483.83057505571 \\
kinetic energy & $=$ & -2977.79156824627
\end{tabular}

Parameters of Level DFT

DFT settings (Functional B3LYP / Gridsize M3)

Geometry optimization options (Energy $10^{-6}$ Hartree, Gradient norm $|\mathrm{dE} / \mathrm{dxyz}|=10^{-3}$ Hartree/Bohr)

Energy minimized coordinates of 9S,10R model of merochlorin at the basis set def-SV(P) for all atoms $(\AA)$.

\begin{tabular}{|l|r|r|r|}
\hline Atom & \multicolumn{1}{|l|}{ X } & \multicolumn{1}{l|}{ Y } & \multicolumn{1}{l|}{} \\
\hline C & 4.39142 & 6.01398 & 3.792149 \\
\hline C & 2.553701 & 5.113861 & 2.154518 \\
\hline C & 2.623896 & 5.646031 & -0.47605 \\
\hline C & 4.686783 & 7.092663 & -1.43741 \\
\hline C & 6.410166 & 7.456283 & 2.813494 \\
\hline C & 6.555507 & 7.978903 & 0.230221 \\
\hline C & 0.438608 & 3.57482 & 3.176034 \\
\hline C & -1.10163 & 1.964625 & 1.298754 \\
\hline C & -1.77686 & 3.668799 & -1.02063 \\
\hline C & 0.610559 & 4.845008 & -2.20002 \\
\hline H & 4.292437 & 5.598619 & 5.809022 \\
\hline H & 8.112732 & 9.087227 & -0.55915 \\
\hline C & 0.503102 & -0.38795 & 0.480959 \\
\hline C & 1.699605 & -1.88297 & 2.620549 \\
\hline H & -0.84947 & -1.59694 & -0.54667 \\
\hline H & 1.925553 & 0.220933 & -0.90425 \\
\hline C & -0.16844 & -3.21065 & 4.359938 \\
\hline H & 0.483753 & -5.10847 & 4.92234 \\
\hline H & -2.01821 & -3.42297 & 3.430782 \\
\hline H & -0.50329 & -2.12376 & 6.117023 \\
\hline C & 4.233033 & -2.07903 & 2.951529 \\
\hline C & 6.224874 & -0.91764 & 1.259423 \\
\hline
\end{tabular}

\begin{tabular}{|l|r|r|r|}
\hline Atom & \multicolumn{1}{|l|}{ X } & \multicolumn{1}{l|}{ Y } & \multicolumn{1}{l|}{ Z } \\
\hline H & 7.34564 & 0.507557 & 2.306232 \\
\hline H & 5.482414 & 0.002278 & -0.45008 \\
\hline H & 7.581875 & -2.387 & 0.640572 \\
\hline C & 5.398276 & -3.56078 & 5.105896 \\
\hline H & 4.038052 & -4.13636 & 6.567274 \\
\hline H & 6.881526 & -2.42304 & 6.045744 \\
\hline H & 6.350842 & -5.28675 & 4.393798 \\
\hline O & -0.1061 & 3.515334 & 5.409261 \\
\hline O & 0.745621 & 5.242319 & -4.48796 \\
\hline O & -3.32805 & 1.192005 & 2.506412 \\
\hline H & -3.10895 & 1.586151 & 4.304656 \\
\hline C & -3.58779 & 5.813454 & -0.26731 \\
\hline H & -2.71455 & 7.074294 & 1.152237 \\
\hline H & -4.08213 & 6.944026 & -1.94453 \\
\hline H & -5.31021 & 4.982309 & 0.547913 \\
\hline Cl & -3.37873 & 1.796889 & -3.41467 \\
\hline O & 8.158388 & 8.279063 & 4.476028 \\
\hline H & 9.458945 & 9.25149 & 3.612794 \\
\hline H & 4.897151 & 7.649653 & -3.87671 \\
\hline H & 3.414483 & 6.860135 & -4.75592 \\
\hline & & & \\
\hline & & & \\
\hline
\end{tabular}


Table SC2. ECD calculation of $(9 R, 10 S)-\mathbf{2 b}$ model of merochlorin

\begin{tabular}{|c|c|}
\hline otal energy & $=-1493.96101296418$ \\
\hline & 1483.82616816 \\
\hline ergy & $=-2977.78718$ \\
\hline
\end{tabular}

Parameters of Level DFT

DFT settings (Functional B3LYP / Gridsize M3)

Geometry optimization options (Energy $10^{-6}$ Hartree, Gradient norm $|\mathrm{dE} / \mathrm{dxyz}|=10^{-3}$ Hartree/Bohr)

Energy minimized coordinates of 9R,10S model of merochlorin at the basis set def-SV(P) for all atoms $(\AA)$.

\begin{tabular}{|l|r|r|r|}
\hline Atom & \multicolumn{1}{|l|}{ X } & \multicolumn{1}{l|}{ Y } & \multicolumn{1}{l|}{ Z } \\
\hline C & 2.423495 & 6.260187 & -9.15436 \\
\hline C & 0.719015 & 6.501096 & -7.17797 \\
\hline C & 0.315167 & 8.849179 & -5.94065 \\
\hline C & 1.759872 & 10.98307 & -6.73567 \\
\hline C & 3.832021 & 8.390713 & -9.92298 \\
\hline C & 3.505185 & 10.71807 & -8.72158 \\
\hline C & -0.73971 & 4.252689 & -6.33969 \\
\hline C & -1.96702 & 4.338992 & -3.69872 \\
\hline C & -3.37303 & 6.926247 & -3.43237 \\
\hline C & -1.58506 & 9.163838 & -3.95093 \\
\hline H & 2.693653 & 4.44298 & -10.0897 \\
\hline H & 4.587762 & 12.38566 & -9.29 \\
\hline C & 0.138051 & 4.033988 & -1.63575 \\
\hline C & 1.954546 & 1.846135 & -2.03192 \\
\hline H & -0.92023 & 3.753844 & 0.13888 \\
\hline H & 1.15468 & 5.835399 & -1.44524 \\
\hline C & 0.76693 & -0.76636 & -1.82373 \\
\hline H & 0.350481 & -1.58497 & -3.70481 \\
\hline H & 1.997312 & -2.1168 & -0.82035 \\
\hline H & -1.04289 & -0.67418 & -0.8017 \\
\hline C & 4.455074 & 2.162948 & -2.49202 \\
\hline C & 5.81623 & 4.675248 & -2.62459 \\
\hline
\end{tabular}

\begin{tabular}{|c|c|c|c|}
\hline Atom & $\mathrm{X}$ & $\mathrm{Y}$ & $\mathrm{Z}$ \\
\hline $\mathrm{H}$ & 4.656151 & 6.318722 & -2.10232 \\
\hline $\mathrm{H}$ & 7.481301 & 4.654399 & -1.3557 \\
\hline $\mathrm{H}$ & 6.555679 & 5.015792 & -4.55316 \\
\hline $\mathrm{C}$ & 6.236593 & -0.03838 & -2.91099 \\
\hline $\mathrm{H}$ & 5.276353 & -1.86005 & -3.18964 \\
\hline $\mathrm{H}$ & 7.425891 & 0.30633 & -4.59764 \\
\hline $\mathrm{H}$ & 7.55889 & -0.24618 & -1.29792 \\
\hline $\mathrm{O}$ & -0.97725 & 2.358916 & -7.62234 \\
\hline $\mathrm{O}$ & -1.85331 & 11.19126 & -2.84211 \\
\hline $\mathrm{O}$ & -3.71683 & 2.359287 & -3.5343 \\
\hline $\mathrm{H}$ & -3.40862 & 1.268724 & -5.00108 \\
\hline $\mathrm{C}$ & -5.62438 & 7.101249 & -5.26168 \\
\hline $\mathrm{H}$ & -6.61998 & 8.909243 & -4.98712 \\
\hline $\mathrm{H}$ & -6.92394 & 5.523877 & -4.87923 \\
\hline $\mathrm{H}$ & -4.99087 & 6.983398 & -7.24954 \\
\hline $\mathrm{Cl}$ & -4.63689 & 7.242444 & -0.25314 \\
\hline $\mathrm{O}$ & 5.484313 & 8.058296 & -11.8355 \\
\hline $\mathrm{H}$ & 6.348375 & 9.635672 & -12.2198 \\
\hline $\mathrm{H}$ & 1.502598 & 13.23733 & -5.66142 \\
\hline $\mathrm{H}$ & 0.1997 & 13.05587 & -4.29583 \\
\hline & & & \\
\hline
\end{tabular}


Table SC3. The major conformers of merochlorins E (2) and F (3) identified by conformational searches in MMFF94 force field using the macromodel

\begin{tabular}{|c|c|c|}
\hline Conformers & Relative energy $(\mathrm{kJ} / \mathrm{mol})$ & Boltzmann population (\%) \\
\hline $14 R \_1$ & 0.0 & 48.734 \\
\hline $14 R 2$ & 1.326 & 28.550 \\
\hline $14 R \_3$ & 3.674 & 11.072 \\
\hline $14 R \_4$ & 5.148 & 6.108 \\
\hline $14 R 5$ & 6.002 & 4.328 \\
\hline $14 R \_6$ & 9.163 & 1.209 \\
\hline $14 S 1$ & 0.0 & 32.224 \\
\hline $14 S_{2} 2$ & 0.578 & 25.519 \\
\hline $14 S 3$ & 2.606 & 11.263 \\
\hline $14 S 4$ & 3.212 & 8.820 \\
\hline $14 S 5$ & 3.554 & 7.682 \\
\hline $14 S 6$ & 4.692 & 4.855 \\
\hline $14 S 7$ & 5.705 & 3.225 \\
\hline $14 S \_8$ & 6.812 & 2.064 \\
\hline $14 S 9$ & 7.253 & 1.728 \\
\hline $14 S 10$ & 8.589 & 1.008 \\
\hline $14 S-11$ & 8.8943 & 0.874 \\
\hline $14 S \_12$ & 9.365 & 0.737 \\
\hline
\end{tabular}


Table SC4. Experimental (Exp.) and calculated (Cal.) chemical shift values (CS, $\delta$ ) of merochlorins E (2) and F (3)

\begin{tabular}{|c|c|c|c|c|}
\hline Atom & Cal. CS of $14 S$ & Cal. CS of $14 R$ & Exp. CS of $\mathbf{2}$ & Exp. CS of $\mathbf{3}$ \\
\hline $\mathrm{C}-5$ & 107.65 & 107.5 & 107.6 & 107.7 \\
\hline C-4 & 161.88 & 161.72 & 164.1 & 164.1 \\
\hline $\mathrm{C}-3$ & 107.17 & 107.89 & 107.3 & 107.4 \\
\hline $\mathrm{C}-2$ & 136.49 & 136.28 & 135.2 & 134.9 \\
\hline $\mathrm{C}-7$ & 112.14 & 112.27 & 107.8 & 107.9 \\
\hline $\mathrm{C}-6$ & 166.47 & 166.25 & 165.6 & 165.7 \\
\hline $\mathrm{C}-1$ & 203.03 & 203.52 & 195.2 & 195.1 \\
\hline $\mathrm{C}-10$ & 89.14 & 89.81 & 83.9 & 83.9 \\
\hline C-9 & 91.3 & 91.23 & 78.0 & 76.0 \\
\hline C-8 & 199.43 & 199.1 & 193.4 & 193.2 \\
\hline $\mathrm{C}-26$ & 34.72 & 35.04 & 18.1 & 18.0 \\
\hline $\mathrm{C}-11$ & 51.55 & 50.98 & 39.5 & 38.4 \\
\hline $\mathrm{C}-12$ & 132.74 & 133.63 & 125.1 & 125.7 \\
\hline $\mathrm{C}-13$ & 42.8 & 41.94 & 34.4 & 33.7 \\
\hline $\mathrm{C}-23$ & 138.05 & 137.35 & 130.9 & 130.5 \\
\hline C-14 & 54.24 & 53.49 & 47.0 & 46.9 \\
\hline C-19 & 38.05 & 38.04 & 32.0 & 32.1 \\
\hline $\mathrm{C}-21$ & 33.78 & 34.18 & 26.3 & 26.4 \\
\hline C-18 & 37.13 & 36.67 & 28.6 & 29.1 \\
\hline $\mathrm{C}-17$ & 30.28 & 30.39 & 22.5 & 22.6 \\
\hline $\mathrm{C}-22$ & 27.03 & 27.04 & 20.8 & 20.7 \\
\hline $\mathrm{C}-24$ & 27.89 & 27.69 & 20.8 & 20.7 \\
\hline $\mathrm{C}-15$ & 140.85 & 140.62 & 136.6 & 136.8 \\
\hline $\mathrm{C}-16$ & 126.43 & 126.97 & 119.4 & 119.9 \\
\hline $\mathrm{C}-24$ & 32.31 & 32.83 & 24.8 & 24.7 \\
\hline $\mathrm{C}-20$ & 35.34 & 36.48 & 28.1 & 27.9 \\
\hline $\mathrm{H}-5$ & 5.71 & 5.64 & 6.63 & 6.62 \\
\hline $\mathrm{H}-3$ & 6.45 & 6.47 & 6.85 & 6.83 \\
\hline $6-\mathrm{OH}$ & 11.22 & 11.19 & 11.47 & 11.47 \\
\hline $4-\mathrm{OH}$ & 3.88 & 3.87 & 11.52 & 11.52 \\
\hline $\mathrm{H}-26$ & 0.69 & 1.3 & 1.80 & 1.79 \\
\hline $\mathrm{H}-26$ & 2.30 & 2.33 & 1.80 & 1.79 \\
\hline $\mathrm{H}-26$ & 1.30 & 0.68 & 1.80 & 1.79 \\
\hline H-11 & 2.99 & 2.61 & 2.69 & 2.56 \\
\hline $\mathrm{H}-11$ & 2.27 & 2.71 & 2.12 & 2.32 \\
\hline $10-\mathrm{OH}$ & 3.06 & 3.21 & 5.95 & 5.99 \\
\hline $\mathrm{H}-13$ & 2.08 & 1.91 & 2.23 & 2.14 \\
\hline $\mathrm{H}-13$ & 1.29 & 1.91 & 1.22 & 1.78 \\
\hline H-14 & 1.58 & 1.56 & 1.50 & 1.41 \\
\hline $\mathrm{H}-21$ & 1.25 & 1.29 & 0.72 & 0.62 \\
\hline $\mathrm{H}-21$ & 0.74 & 0.67 & 0.72 & 0.62 \\
\hline H-21 & 0.54 & 0.51 & 0.72 & 0.62 \\
\hline
\end{tabular}


Figure SC2. Evaluation of similarity factors of ECD spectra of meroindenon by SpecDis ${ }^{\mathrm{a}}$

Similarity factor between experimental and calculated ECD spectra of meroindenon $=54.90 \%$

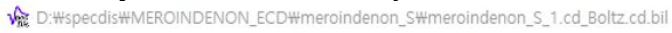

File ECD UV VCD IR ORD Compare Tools about

UVIECD $\mid$ IRNCD $\mid$ HPLC | ORD |

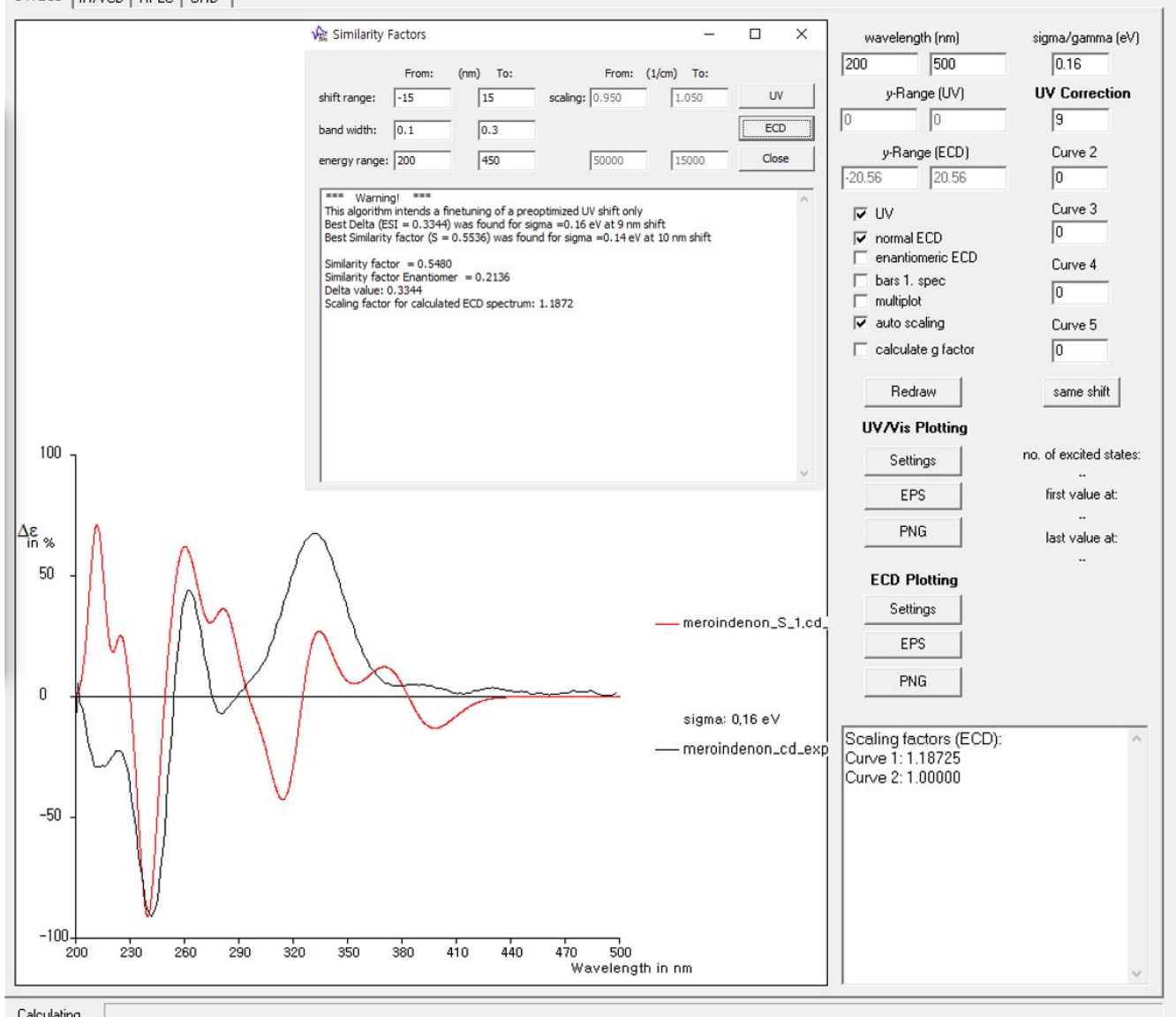

${ }^{\mathrm{a}}$ Chirality 2013, 25, 243-249 
Figure SC3. Evaluation of similarity factors of ECD spectra of partial structure of merochlorins by SpecDis ${ }^{\mathrm{a}}$

Similarity factor between experimental and calculated ECD spectra of partial structure of merochlorins $=80.68 \%$

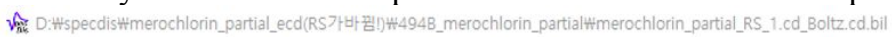

File ECD UV VCD IR ORD Compare Tools about

UV/ECD $\mid$ IRNCD | HPLC | ORD |

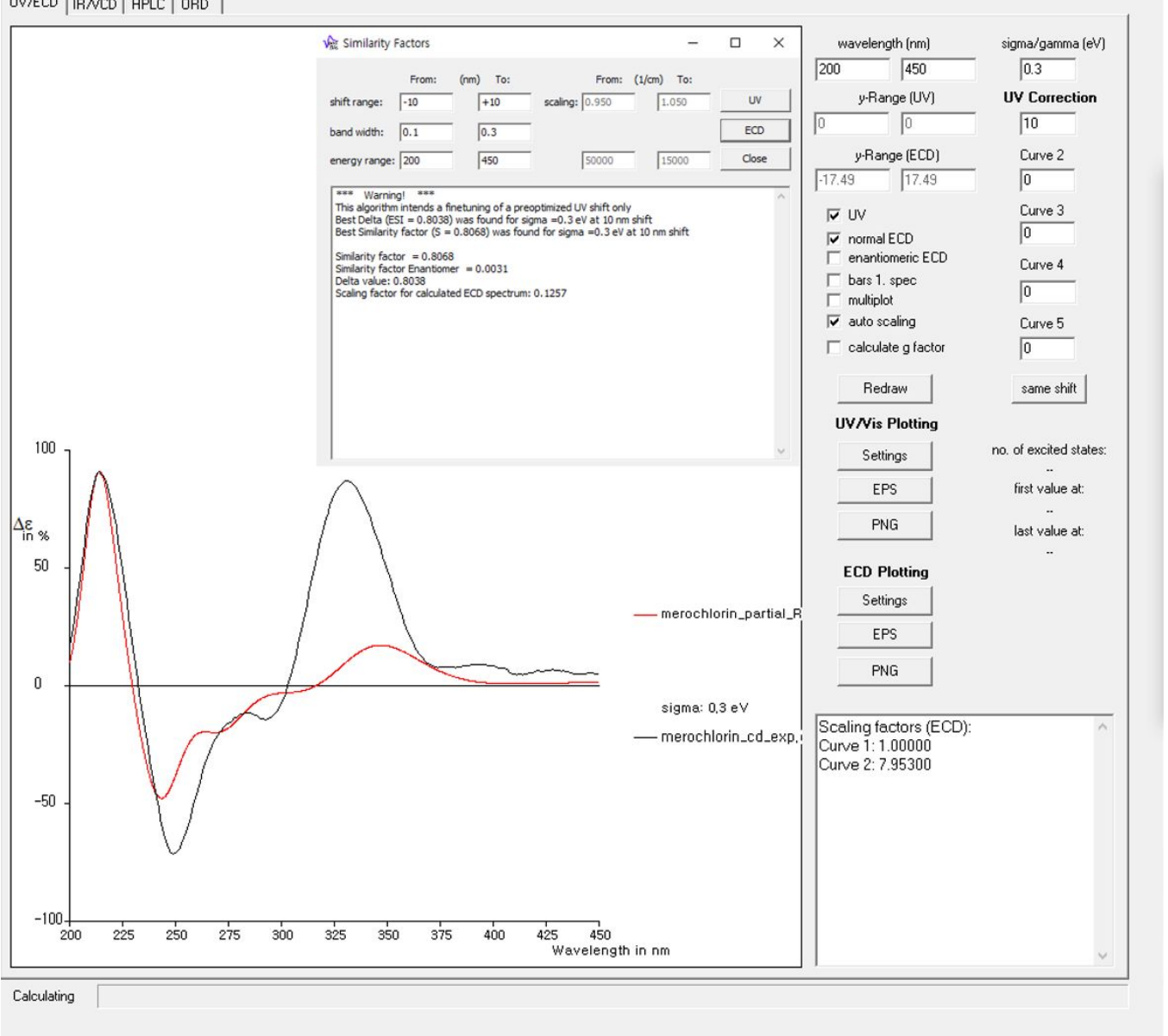

${ }^{\mathrm{a}}$ Chirality 2013, 25, 243-249 
Figure SC4. ECD calculation of full structure models of merochlorin E (2)

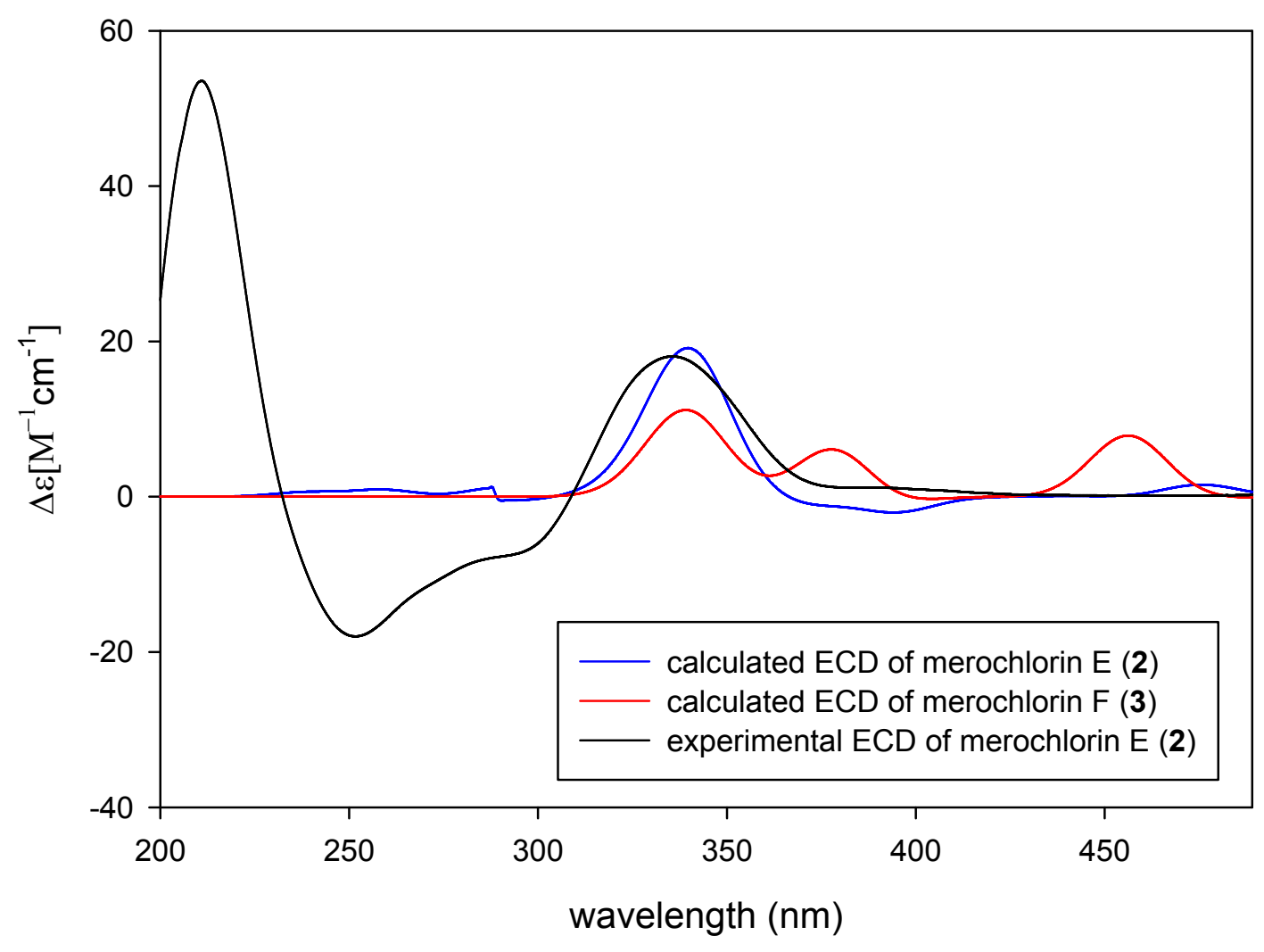


Figure SC5. ECD calculation of full structure models of merochlorin F (3)

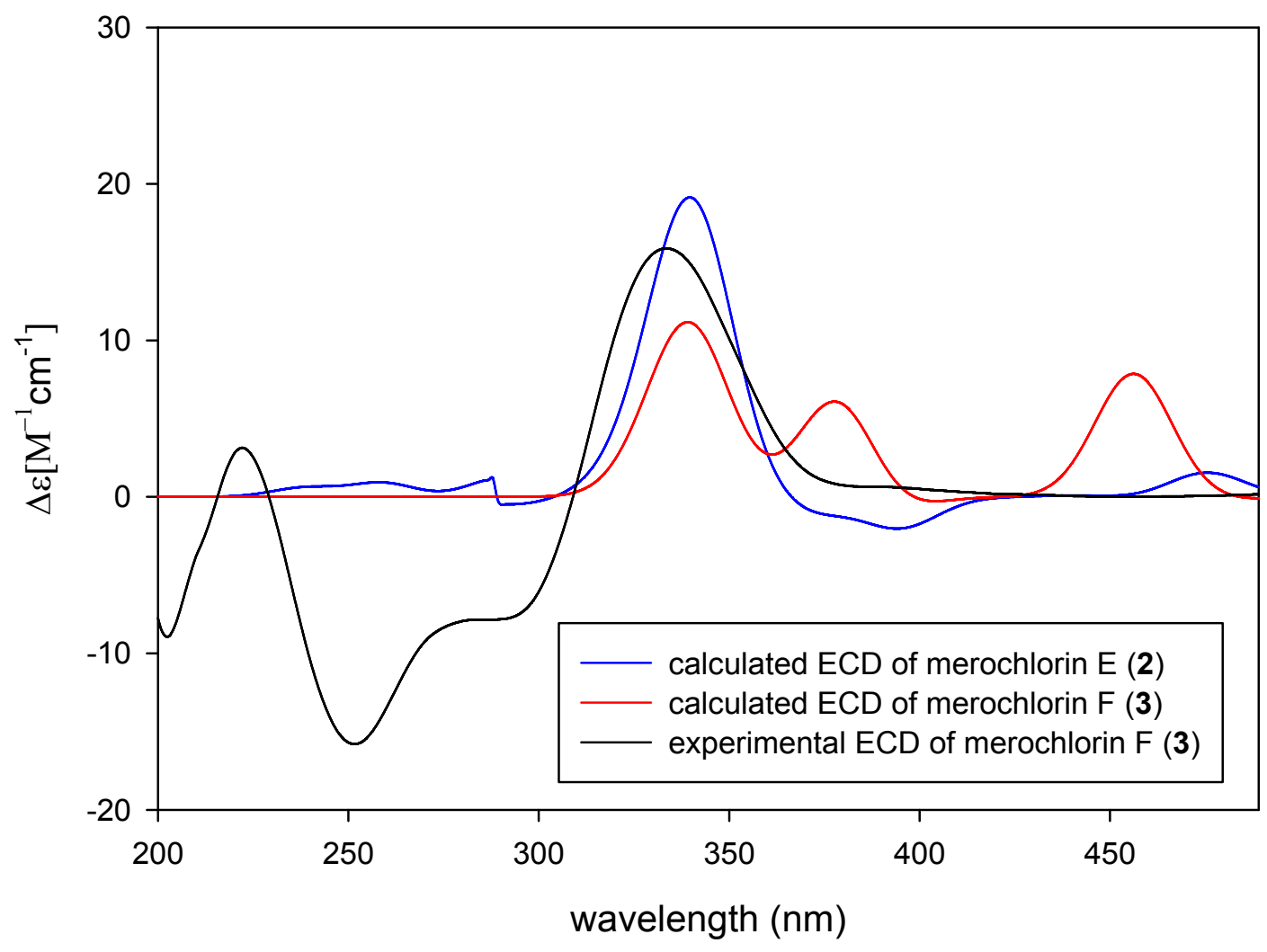

